\title{
Review Article \\ Integrin Signaling in Cancer Cell Survival and Chemoresistance
}

\author{
Fawzi Aoudjit $^{1}$ and Kristiina Vuori $^{2}$ \\ ${ }^{1}$ Pavillon CHUL, Centre de Recherche du CHUQ and Faculté de Médecine, Université Laval, Québec, QC, Canada G1V 4 G2 \\ ${ }^{2}$ Cancer Research Center, Sanford-Burnham Medical Research Institute, La Jolla, CA 92037, USA
}

Correspondence should be addressed to Fawzi Aoudjit, fawzi.aoudjit@crchul.ulaval.ca and

Kristiina Vuori, kvuori@sanfordburnham.org

Received 18 November 2011; Accepted 10 February 2012

Academic Editor: Hamid Morjani

Copyright ( $\odot 2012$ F. Aoudjit and K. Vuori. This is an open access article distributed under the Creative Commons Attribution License, which permits unrestricted use, distribution, and reproduction in any medium, provided the original work is properly cited.

\begin{abstract}
Resistance to apoptosis and chemotherapy is a hallmark of cancer cells, and it is a critical factor in cancer recurrence and patient relapse. Extracellular matrix (ECM) via its receptors, the integrins, has emerged as a major pathway contributing to cancer cell survival and resistance to chemotherapy. Several studies over the last decade have demonstrated that ECM/integrin signaling provides a survival advantage to various cancer cell types against numerous chemotherapeutic drugs and against antibody therapy. In this paper, we will discuss the major findings on how ECM/integrin signaling protects tumor cells from drug-induced apoptosis. We will also discuss the potential role of ECM in malignant T-cell survival and in cancer stem cell resistance. Understanding how integrins and their signaling partners promote tumor cell survival and chemoresistance will likely lead to the development of new therapeutic strategies and agents for cancer treatment.
\end{abstract}

\section{Introduction}

Integrins are $\alpha / \beta$ heterodimeric membrane receptors that mediate cell-cell interactions and cell attachment to extracellular matrix (ECM). In addition to their role as cell adhesion molecules, ligation of integrins with ECM ligands induces a variety of intracellular signals and regulates several cellular responses including migration, differentiation, and proliferation [1-3]. Moreover, integrins also modulate programmed cell death or apoptosis. Most notably, many types of normal cells are absolutely dependent on proper ECM-integrin ligation for their survival. In cell culture experiments, lack of attachment of endothelial and epithelial cells to a proper matrix protein has been shown to induce a form of apoptosis that was termed anoikis $[4,5]$. Since these ground-breaking studies, the role of integrin-ECM interactions in regulating cellular life and death has been the focus of extensive studies in the last decade. An intense area of research includes the understanding of integrin prosurvival function in the modulation of the chemotherapeutic response of cancer cells. Anticancer drugs used in chemotherapy are thought to exert their cytotoxic effects partially via induction of apoptosis [6]. Thus, a prevailing hypothesis is that cancer cell's resistance to apoptosis contributes to the development of drug resistance, which is an important factor in clinical relapse of cancer patients treated with chemotherapy. Initial studies have reported that integrin-ECM interactions can protect small cell lung cancer cells [7], multiple myeloma cell lines [8], and glioma cell lines [9] from drug-induced apoptosis. Further studies have extended the role of integrins in chemoresistance to other cancer cell types including various hematological malignancies and to several different classes of chemotherapeutic agents [10-14]. Integrins also provide survival advantage against death receptor-mediated apoptosis suggesting that they can promote cancer immune escape [15-19].

Herein, we will briefly review the role of integrins in apoptosis signaling and will discuss the major findings as to how the integrins may play a key role in the resistance of cancer cells to apoptosis and chemotherapy.

\section{Programmed Cell Death (Apoptosis)}

There are two major cellular death pathways that transduce the effects of various death inducers, including anticancer chemotherapeutic drugs. The extrinsic death pathway is 
mediated through cell death receptors of the TNF receptor family, such as the Fas receptor, whereas the intrinsic death pathway proceeds through the mitochondria [2022]. Ligation of Fas with its ligand Fas-L induces Fas receptor aggregation, which in turn recruits the cytosolic adapter protein FADD to form the death inducing signaling complex (DISC). Caspase-8 is then recruited to the DISC and gets activated through aggregation and proteolytic cleavage. Activated caspase- 8 in turn leads to the activation of executioner caspases such as caspase-3 $[20,22]$.

The mitochondrial cell death is regulated by a balance between pro- and antiapoptotic Bcl-2 family of proteins [23-25]. Apoptotic stimuli that activate the mitochondrial death pathway lead to the activation of Bcl-2 proapoptotic proteins and inactivation of the $\mathrm{Bcl}-2$ antiapoptotic proteins. Consequently, proapoptotic Bcl-2 proteins such as Bax/Bak become activated, which will cause the permeabilization of the mitochondria. This in turn leads to the release of apoptotic factors from mitochondria, among which is cytochrome c. Following its release, cytosolic cytochrome c binds to the adaptor protein Apaf-1, which in the presence of dATP recruits procaspase-9, thereby forming the apoptosome complex and leading to the activation of caspase- 9 . Activated caspase- 9 then activates executioner caspases [2025].

In the so-called type II cells, activation of caspase- 8 at the DISC is weak upon engagement of the extrinsic death pathway, and the apoptotic signal becomes amplified by the mitochondrial death pathway. In type II cells, activated caspase- 8 at the DISC cleaves the proapoptotic Bcl-2 protein Bid, which then translocates to the mitochondria and activates Bax, leading to mitochondria permeabilization and subsequent activation of caspase-9. Caspase- 9 then functions in concert with caspase-8, activating the executioner caspases [20-22].

Initial studies have indicated that both of these apoptotic pathways can be important for the induction of apoptosis by chemotherapeutic agents. However, it is now clear that the mitochondrial death pathway is involved in the apoptotic action of most of the chemotherapeutic agents $[6,26,27]$. As it will be discussed below, integrins are able to modulate both the intrinsic and extrinsic apoptotic pathways.

\section{Integrins and Cell Signaling}

Integrins are cell surface membrane receptors composed of $\alpha$ and $\beta$ chain heterodimers with short cytoplasmic tails devoid of any enzymatic activity. There are 18 different $\alpha$ chains and $8 \beta$ subunits in humans, which associate in pairs to give rise to at least 24 distinct $\alpha / \beta$ integrin heterodimers [28]. The $\beta 1$ integrin subfamily is composed of 12 members as defined by the participating $\alpha$ subunit $(\alpha 1-\alpha 12)$, is widely expressed, and constitutes a major class of integrins that mediate cell interactions with matrix proteins. The $\alpha 1 \beta 1$ and $\alpha 2 \beta 1$ integrins are major collagen receptors, whereas $\alpha 4 \beta 1$ and $\alpha 5 \beta 1$ integrins bind fibronectin, and $\alpha 3 \beta 1$ and $\alpha 6 \beta 1$ are receptors for laminins [28].

Upon ligand binding, integrins form clusters on the cell surface at cellular sites termed focal adhesions that act not only as structural links between the ECM and the actin cytoskeleton but also as sites of signal transduction from the ECM to intracellular signaling pathways $[1,29,30]$. Focal adhesion kinase (FAK), integrin-linked kinase (ILK), and Src kinases have all been shown to be activated by integrin ligand binding [1,29-31]. The ability of integrins to regulate apoptosis is likely due to their capacity to activate the cell survival signaling pathways further downstream of these cytoplasmic protein kinases, composed of phosphatidylinositol $3^{\prime}$-kinase (PI 3-kinase) and the serine/threonine kinase AKT, as well as the mitogen-activated protein kinase/extracellular regulated kinase (MAPK/ERK). The signaling events by which integrins activate these survival pathways are complex and may be tissue specific, but the dual kinase complex of FAK/Src has been shown to be involved in the activation of these survival pathways $[1,32]$.

\section{Role of Integrin Signaling in Drug Resistance}

Cultured cancer cells of epithelial origin typically are able to survive when denied attachment, suggesting that integrin ligand binding is no longer required to protect cancer cells from anoikis [33, 34]. Accordingly, resistance to anoikis contributes to anchorage-independent growth properties of cancer cells. Integrin-mediated cell attachment, however, has been shown to be required for cancer cell invasion and metastasis $[2,35,36]$, and survival under various deathinducing conditions [34]. Most notably, the implication of integrin-ECM interactions in cell survival and resistance to chemotherapy seems to be a general phenomenon and occurs in multiple types of solid cancers including breast, lung, prostate, ovary, pancreatic and colon cancers, as well as in hematological malignancies, as reviewed below.

\subsection{Solid Tumors}

4.1.1. Breast Cancer. We have shown in breast cancer cell lines MDA-MB-231 and MDA-MB-435 that ligation of $\beta 1$ integrins inhibits apoptosis induced by paclitaxel and vincristine, two microtubule-directed chemotherapeutic agents widely used in the therapy of breast cancer [37]. We showed that attachment of MDA-MB-231 cells to fibronectin and to type I collagen via $\alpha 5 \beta 1$ and $\alpha 2 \beta 1$ integrins, respectively, significantly reduced drug-induced apoptosis. However, neither of these integrins/ligands had any effect on the survival of the MDA-MB-435 cells. In contrast, we found that it is the laminin-1-binding integrin $\alpha 6 \beta 1$ that mediates the protective effect against drug-induced apoptosis in these cells. It is noteworthy that more recent studies have found that the MDA-MB-435 originates from melanoma rather than from breast cancer [38] suggesting that $\beta 1$ integrin can also protect melanoma cells from drug-induced apoptosis. Our results further indicated that the protective effect of $\beta 1$ integrin in these cancer cells is mediated via activation of the PI 3-kinase/AKT pathway, which prevented the downregulation of Bcl-2 protein levels and inhibited drug-induced cytochrome $\mathrm{c}$ release upon drug treatment. These results indicate that $\beta 1$ integrins inhibit drug-induced apoptosis at the level of the mitochondria. 
Importantly, laminin and fibronectin have also been shown to protect MDA-MB-231 cells and A549 lung cancer cells from radiation-induced apoptosis and from the cytotoxic drug ukrain [39].

More recently, the Hemler laboratory reported that resistance of ErbB2-positive breast cancer cells to antiErb2 agents can be overcome by disrupting cell adhesion [40]. ErbB2 is an oncogene associated with higher grades of breast carcinomas. It is a member of the epidermal growth factor receptor family, also known as the human epidermal growth factor receptor 2 (HER2) [41]. Hemler and coworkers showed that adhesion of human Erb2positive breast cancer cells to laminin-5 provided significant resistance to trastuzumab and lapatinib, an antibody and a small-molecule, respectively, that target ErbB2. The laminin5 effect is mediated via $\alpha 3 \beta 1$ and $\alpha 6 \beta 4$ integrins and the associated tetraspanin CD151 receptor, and via downstream signaling through AKT, ERK1/2, and FAK. Another study reported that expression of $\beta 1$ integrins is inversely correlated with the sensitivity of HER-2-positive breast cancer cells to trastuzumab treatment, suggesting that the $\beta 1$ integrin is a potentially novel independent prognostic biomarker of trastuzumab response in HER-2-positive metastatic breast cancer patients [42]. ErbB-2 also mediates transcriptional upregulation of the $\alpha 5 \beta 1$ fibronectin receptor, and adhesion to fibronectin promotes cell survival in several conditions including hypoxia, serum starvation, and chemotherapy [43]. Furthermore, by using human breast cancer cell lines and a series of breast cancer biopsies from patients undergoing tamoxifen therapy, it was found that $\alpha 6 \beta 4$ integrin contributes to tamoxifen resistance via induction of ErbB-3 expression, which leads to an increase in AKT activation [44]. This seems to occur mainly in the estrogenreceptor-beta-1- (ERbeta1-) negative breast carcinomas. The authors found that, in these tumors, ErbB-3 inactivation inhibits AKT phosphorylation and induces apoptosis, thus favouring tamoxifen response. The analysis of human tumor biopsies revealed a significant correlation between $\alpha 6 \beta 4$ integrin/ErbB-3/phosphorylated-AKT signaling axis in ERbeta1-negative breast cancers derived from patients with lower disease-free survival. Together these studies indicate that ErbB oncogenic function in breast cancer cells is tightly regulated by integrin signaling, further supporting the role of integrins in breast cancer chemoresistance and survival. Furthermore, these studies show that in addition to DNA-damaging agents and microtubule-directed drugs, integrins in breast cancer cells also regulate resistance to drugs targeting specific oncogenes and steroid receptors.

Fibronectin, collagens, and laminins are important matrix proteins of the breast cancer tumor microenvironment. The $\alpha 2 \beta 1$ integrin seems to be important for integrinmediated attachment to collagen type I during metastasis of breast cancer cells to the bone $[45,46]$. Of note, however, a recent study suggested that $\alpha 2 \beta 1$ integrin might suppress metastasis of breast cancer cells to the lymph nodes [47]. Gene expression analysis of drug-resistant MCF7 breast cancer cells revealed that 25 genes encoding various ECM proteins (collagen, fibronectin, syndecan, laminin) and integrin subunits were upregulated in drug-resistant MCF7 cells [48]. A clinical study also reported that increased $\beta 1$ integrin expression is associated with decreased survival in invasive breast cancer [49], and inhibition of $\beta 1$ integrin enhanced radiotherapy in human breast cancer xenografts [50].

The studies described above indicate that the integrinECM signaling is a critical pathway in breast cancer resistance to chemotherapy. The role of a specific $\beta 1$ integrin molecule is likely to be dependent on the differentiation status of the breast tumor (i.e., whether tumor is ErbB positive, invasive, etc.) and on the nature of the drug utilized. In this regard, laminin receptors are emerging as major integrins mediating breast cancer chemoresistance. A scheme summarizing the prosurvival role of laminin-binding integrins in breast cancer is depicted in Figure 1.

4.1.2. Other Solid Tumors. Sethi et al. reported that adhesion of small cell lung cancer cells to fibronectin, collagen IV, and laminin inhibited apoptosis induced by chemotherapeutic agents including etoposide, cis-platinum, and daunorubicin as well as radiation [7]. The effect is mediated via $\beta 1$ integrins among which $\alpha 2 \beta 1, \alpha 3 \beta 1, \alpha 6 \beta 1$, and $\alpha \mathrm{v} \beta 1$ are the most expressed on these cells. Furthermore, the protective effect of $\beta 1$ integrins is mediated through activation of the PI 3-kinase/AKT pathway, which inhibited drug-induced cell cycle arrest and caspase-3 activation [51]. The authors further showed that integrin-mediated activation of PI 3kinase/AKT survival pathway overrides apoptosis by reducing the levels of p21 and p27 cell cycle inhibitors and by preventing downmodulation of cyclins $\mathrm{E}, \mathrm{A}$, and $\mathrm{B}$. Consequently, chemotherapeutic agents are unable to induce G2/M cell cycle arrest, which is a necessary step in drug-induced apoptosis. In addition, the protective role of $\beta 1$ integrin signaling did not occur at the level of DNA repair, indicating that the integrin-PI 3-kinase/AKT signaling pathway allows small cell lung cancer cells to survive chemotherapy despite DNA damage. Immunohistochemistry analysis of small cell lung cancer biopsies has revealed that these tumors produce large amounts of collagen IV, which could bind to $\alpha 2 \beta 1$ or $\alpha 3 \beta 1$ integrins, and fibronectin, which is a ligand for the $\alpha \mathrm{v} \beta 1$ integrin $[52,53]$.

A clinical study performed with transbronchial biopsies found that increased expression of $\beta 1$ integrins correlates with chemoresistance and is a poor prognostic factor in small cell lung cancer [54]. Moreover, high levels of $\beta 1$ expression and p53 were found to be a greater poor prognostic factor than clinical stage in small cell lung cancer [55]. Overexpression of $\beta 1$ integrins has also been associated with the resistance of non-small-cell lung cancer to the tyrosine kinase inhibitor gefitinib, which targets the epidermal growth factor receptor tyrosine kinase [56]. Together these studies emphasize the critical role of $\beta 1$ integrins in the malignancy and chemoresistance in lung cancer.

Additional solid tumors also use attachment to ECM to escape apoptosis and chemotherapy. Thus, fibronectin inhibits ceramide- and docetaxel-induced apoptosis in the prostate cancer cell line DU145 via $\beta 1$ integrins and insulin-like growth factor [57]. Parathyroid hormone-related 


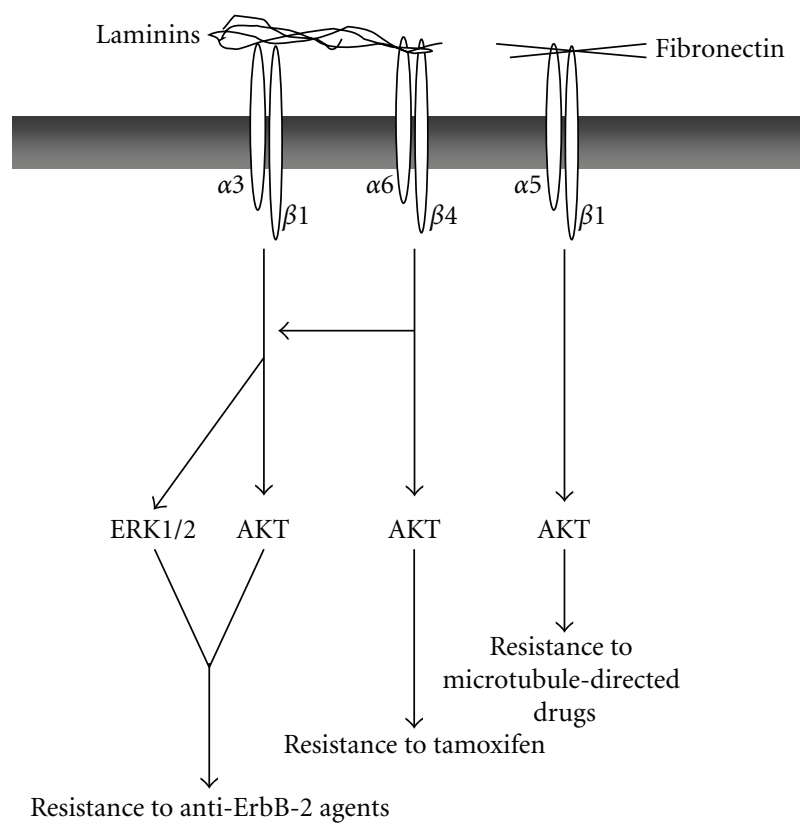

Figure 1: Laminin and fibronectin-mediated resistance to druginduced apoptosis in breast cancer. Ligation of $\alpha 3 \beta 1, \alpha 6 \beta 4$, and $\alpha 5 \beta 1$ integrins with laminins and fibronectin, respectively, protects breast cancer cells from several cytotoxic agents via the activation of the PI 3-kinase/AKT and MAPK/ERK survival pathways.

protein in turn protects C4-2 and PC-3 prostate cancer cells from doxorubicin-induced apoptosis through integrin $\alpha 6 \beta 4$ mediated activation of the PI 3-kinase/AKT survival pathway [58]. Here, the parathyroid hormone-related protein $/ \alpha 6 \beta 4$ integrin/PI 3-kinase/AKT signaling axis leads to an increase in the ratio of antiapoptotic to proapoptotic members of the Bcl-2 family and to activation of the transcription factor $\mathrm{NF} \kappa \mathrm{B}$, which is known to upregulate the expression of several antiapoptotic proteins.

Interactions of pancreatic cancer cells with ECM including fibronectin, collagen type I, and collagen type IV decreased their sensitivity to cytotoxic drugs and promoted cell proliferation [59]. Furthermore, intrinsic chemoresistance to gemcitabine in these tumors correlates with constitutive laminin-induced FAK activation [60]. Activated FAK was shown to be required for activation of AKT, which mediates an increase in the expression of the anti-apoptotic protein survivin, and the inactivation of the Bcl-2 proapoptotic factor Bad via phosphorylation. A recent study also reported that pancreatic stellate cells can protect pancreatic cancer from radiotherapy-induced apoptosis through $\beta 1$ integrin signaling involving FAK [61]. In addition, collagen I binding to $\alpha 2 \beta 1$ integrin has been shown to promote the malignant phenotype of pancreatic ductal adenocarcinoma and to protect from $5^{\prime}$-fluourouracil (antimetabolite drug)induced apoptosis by upregulating the antiapoptotic protein Bcl-2 family member Mcl-1 [62]. Cell coculture models and human biopsies analysis have revealed that pancreatic tumors are enriched in the expression of several ECM proteins including collagens, fibronectin, and laminin [63]. The fibronectin receptor $\alpha 5 \beta 1$ also transduces the antiapoptotic effect of the adhesion molecule L1CAM (CD171) [64], and L1CAM/CD171 is associated with poor prognosis in several cancers such as colon and ovarian cancers [65]. Treatment of pancreatic cancer cells with chemotherapeutic drugs induces the expression of L1CAM, which binds to $\alpha 5 \beta 1$ integrin thus favoring chemoresistance. The prosurvival effect of L1CAM binding to the $\alpha 5 \beta 1$ integrin seems to be associated with activation of $\mathrm{NF} \kappa \mathrm{B}$ and production of IL- $1 \beta[66]$.

The studies above point to a major role of PI3 kinase/AKT pathway in the chemoresistance of solid tumors. A scheme summarizing the mechanisms by which activation of PI3 Kinase/AKT promotes integrin-mediated chemoresistance is depicted in Figure 2.

4.2. Hematological Malignancies. Integrin-ECM signaling is also important for the survival of malignant cells of the hematopoietic origin. Several studies over the last decade have pointed to the $\alpha 4 \beta 1$ integrin as the principal ECM receptor involved in the survival and chemoresistance of multiple myeloma, myeloid, and B lymphoid malignancies. The role of the $\alpha 4 \beta 1$ integrin in these hematological malignancies has been outstandingly reviewed [11-14] and will not be the focus here. However, the $\alpha 4 \beta 1$ integrin does not seem to be as important for the survival of malignant $\mathrm{T}$ cells. The role of ECM in the survival and chemoresistance of T-cell neoplasms, which also grow in sites rich in ECM, remains poorly addressed. Several recent studies point to collagen-binding integrins as the major molecules involved in both normal and malignant T-cell survival. Below, we will discuss the expression and function of the $\beta 1$ integrins in the T-cell lineage and how they contribute to the resistance of malignant T cells.

\subsubsection{Expression of ECM Receptors in the T-Cell Lineage.} Normal T cells express several $\beta 1$ integrins, which mediate their adhesion to fibronectin, laminin, and collagens [67]. Previously, $\beta 1$ integrins and especially fibronectin receptors have been proposed to play an important role in T-cell adhesion and in T-cell costimulation and activation [6870]. However, the collagen-binding integrins $\alpha 1 \beta 1$ and $\alpha 2 \beta 1$ have recently gained more attention as putative regulators of T-cell-mediated immunity and inflammation [67, 71, 72]. They are expressed only on effector $\mathrm{T}$ cells, which home to the inflamed tissues, whereas other $\beta 1$ integrins such as fibronectin and laminin receptors are also found on naïve $\mathrm{T}$ cells. In addition, collagen is a more potent costimulatory molecule of human effector T cells than fibronectin [73], and we have shown that $\alpha 2 \beta 1$ integrin enhances the production of IFN $\gamma$ and IL-17 in effector T cells $[74,75]$, two cytokines that play a crucial role in autoimmunity and tissue damage. $\mathrm{T}$ cells infiltrating inflamed sites in arthritis and other chronic inflammatory diseases can also express $\alpha 1 \beta 1$ and $\alpha 2 \beta 1$ integrins $[76,77]$. Animal studies with mutant mice and blocking antibodies have demonstrated a critical role for the $\alpha 2 \beta 1$ integrin in the development of multiple sclerosis [78] and for both $\alpha 1 \beta 1$ and $\alpha 2 \beta 1$ integrins in delayedtype hypersensitivity and in arthritis [79, 80]. Together, these studies indicate that collagen-binding integrins can be 


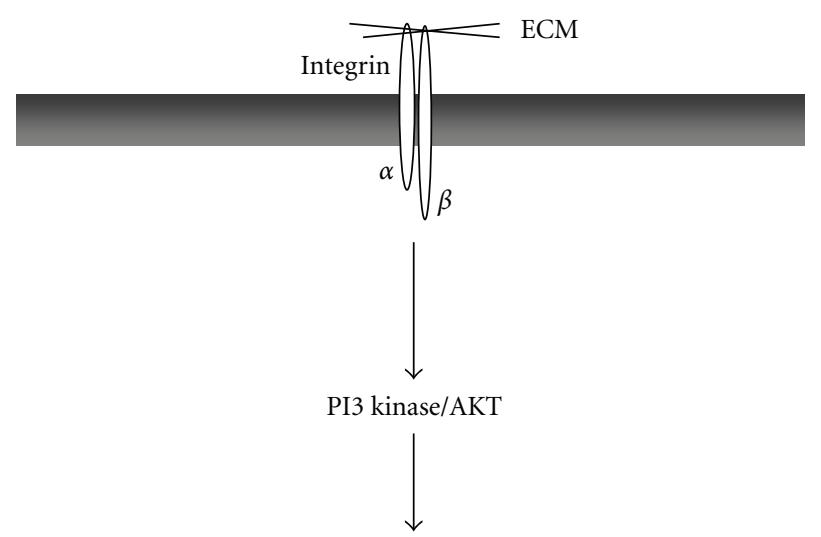

(1) Upregulation of Bcl-2, Mcl-1 and inhibition of Bad

(2) Upregulation of survivin

(3) Upregulation of cyclin A, B, E and downmodulation of p21 and p27

(4) Activation of $\mathrm{NF} \kappa \mathrm{B}$ (and transcription of various antiapoptotic genes)

FIgURE 2: Role of PI 3-kinase/AKT in integrin-mediated drug resistance. Integrin/ECM interactions lead to the activation of PI 3-kinase/AKT which can regulate various downstream targets including proteins of the Bcl-2 family and of the IAP family, as well as cell cycle regulators. It also activates the transcription factor $\mathrm{NF} \kappa \mathrm{B}$, which is known to increase expression of several antiapoptotic proteins.

crucial mediators of T-cell activation that is associated with the development of autoimmune diseases.

Malignant $\mathrm{T}$ cells also express several $\beta 1$ integrins. A number of T-cell acute lymphoblastic leukemia (T-ALL) cell lines such as Jurkat, HSB-2, and CEM express receptors for collagens, fibronectin, and laminins [81-84]. Previous reports have indicated that the collagen-binding integrin $\alpha 1 \beta 1$ is a predominant integrin expressed in cutaneous Tcell lymphomas and was proposed to be the major receptor mediating adhesion of these lymphomas to collagen I and collagen IV $[85,86]$. Malignant cells such as T-ALL or T cell lymphoma also develop and grow in tissues rich in ECM such as the bone marrow, which is a privileged site for all hematological malignancies [12-14, 87, 88]. The niches for leukemia proliferation in the bone marrow are found in the epiphysial region [89], which consists of trabecular bone with spaces containing the red bone marrow. Immunohistochemical analysis has shown that collagen I is widely distributed in the trabeculae as well as throughout the marrow [90, 91], suggesting that collagen I, a major ECM component, could directly regulate interactions and anchorage of leukemia cells in their microenvironment. Clinical and experimental studies have shown that leukemia/lymphoma $\mathrm{T}$ cells can disseminate to organs such as liver, kidneys, and lungs [9295], which are rich in ECM. Thus, ECM present in the microenvironment of lymphoid tumors is likely to regulate their survival.

\subsubsection{ECM/ß1 Integrin in the Survival of Malignant T Cells.}

(1) Regulation of Death Receptor-Mediated Apoptosis in $T$ Cells. The findings that anoikis can be mediated via activation of the death receptor pathway $[96,97]$ prompted us to examine if ECM can protect $\mathrm{T}$ cells from Fas-induced apoptosis, which is a major apoptotic pathway activated during immune response. Fas-induced apoptosis is critical in the maintenance of T-cell homeostasis at the end of immune response, and resistance to Fas-mediated death can contribute to inflammatory diseases and autoimmunity. Activation of the Fas pathway occurs in response to $\mathrm{T}$ cell-receptor- (TCR-) dependent stimulation also known as activation-induced cell death (AICD) [20,98]. Restimulation of activated T cells through the TCR results in the transcriptional activation of Fas and its ligand (Fas-L) genes. Subsequently, ligation of Fas receptor with Fas-L induces apoptosis via DISC formation and caspase- 8 activation.

Using the leukemic Jurkat T-cell line, which is sensitive to AICD and which constitutively expresses several $\beta 1$ integrin members, we have demonstrated that engagement of the $\alpha 2 \beta 1$ integrin with collagen I inhibits AICD [15]. Ligation of $\alpha 2 \beta 1$ with collagen I or with an activating anti- $\alpha 2$ integrin monoclonal $\mathrm{Ab}(\mathrm{mAb})$ significantly reduced TCRdependent apoptosis as well as PMA+Ionomycin-induced apoptosis, which is also partially mediated by the Fas-L/Fas death pathway. However, other matrix proteins such as fibronectin and laminin had no effect. Similarly, ligation of $\alpha 1 \beta 1$ with collagen IV also protected Jurkat T cells from AICD (our unpublished observations). The prosurvival effect of collagen-binding integrins observed in Jurkat Tcells also occurs in normal effector $\mathrm{T}$ cells $[17,99]$. These observations indicate that collagen-binding integrins could promote autoimmune diseases by enhancing effector $\mathrm{T}$ cell survival and they could also promote T-cell malignancies.

Activation of Jurkat $\mathrm{T}$ cells with collagen I did not affect the expression of Fas receptor, which is expressed constitutively at high levels in these cells, but significantly reduced the transcriptional activation of the Fas- $L$ gene upon TCR stimulation. Jurkat $\mathrm{T}$ cells activated with antiTCR/CD3 mAb+collagen I are less efficient than Jurkat $\mathrm{T}$ cells activated by TCR/CD3 alone in killing the Fas-sensitive Hut-78 lymphoma used as target cells [15].

As noted above, focal adhesion kinase (FAK) has been shown to be central in integrin-mediated signaling and cell survival [100]. We have found that FAK is activated by both anti-CD3 $\mathrm{mAb}$ and collagen I, and expression of a dominant-negative form of FAK known as FRNK abrogated the protective effect of collagen I on Fas-L expression and AICD. These studies indicate that $\alpha 2 \beta 1$ integrin-mediated inhibition of AICD is dependent on the activation of FAK and inhibition of Fas-L. The potential role of integrinmediated adhesion in the regulation of death ligands of the TNF family is also underscored in studies performed with adherent cells and could be one mechanism that regulates anoikis. We and others have demonstrated that the culture of endothelial and intestinal epithelial cells in suspension results in the transcriptional increase of death receptor ligands such as Fas-L and TRAIL, which subsequently triggers the activation of death receptor apoptotic cascades, thus contributing to the execution of anoikis [101-103].

We have subsequently investigated if activation of the $\alpha 2 \beta 1$ integrin with collagen I can directly regulate Fas 
signaling, thereby contributing to the inhibition of AICD. This was investigated in Jurkat $\mathrm{T}$ cells stimulated with the agonistic anti-Fas antibody $\mathrm{CH} 11$ to induce apoptosis directly through Fas receptor and independently from TCR stimulation [17]. In these conditions, we have found that collagen I significantly reduced Fas-induced apoptosis of Jurkat $\mathrm{T}$ cells. Interestingly, matrix proteins such as fibronectin and laminin that did not inhibit TCR-dependent apoptosis also had no effect on Fas-induced apoptosis [17]. Furthermore, inhibition studies with dominant negative forms and chemical inhibitors demonstrated that $\alpha 2 \beta 1$-mediated inhibition of Fas-induced apoptosis proceeds through activation of the MAPK/ERK survival pathway and inhibition of caspase8 activation [17]. It is unclear whether the inhibition of caspase- 8 was due to a reduction in DISC formation or to the reduction of proteolytic cleavage of procaspase8. Along these lines, Eriksson's group demonstrated that activation of MAPK/ERK can block Fas-induced apoptosis by inhibiting the autoproteolytic activation of procaspase- 8 [104], whereas Kaufmann's group showed that FADD, which is essential for DISC formation and caspase- 8 activation, can be phosphorylated by MAPK/ERK, thereby contributing to the inhibition of DISC formation [105]. Collagen I may also modulate the localization of c-Flip, an endogenous inhibitor of caspase- 8 activation at the DISC. This mechanism has been proposed to be downstream of the $\alpha 4 \beta 1$ integrin in the inhibition of Fas-induced apoptosis in monocytic U937 cells [19]. In addition, we found that collagen I also reduces TRAIL-induced apoptosis of Jurkat T cells [17]. Notably, the modulation of death receptor-mediated apoptosis by ECM also occurs in solid tumors. Fibronectin protects prostate cancer cells from TNF-induced apoptosis by activating AKT and upregulating the antiapoptotic protein survivin [16]. Ovarian cancer ascites inhibits TRAIL-induced apoptosis of ovarian cancer cells through $\alpha \mathrm{v} \beta 5$ integrin-mediated FAK and AKT activation [18]. Together these studies indicate that, by protecting tumor cells from death receptor-mediated apoptosis, integrins can also contribute to tumor immune escape.

The findings that only collagen but not fibronectin or laminin receptors regulate death-receptor-induced apoptosis in malignant $\mathrm{T}$ cells is likely due to the differential ability of $\beta 1$ integrin members to activate the MAPK/ERK survival pathway. Indeed, only collagen I was able to activate the MAPK/ERK pathway $[17,106]$. We found that collagen I activates the MAPK/ERK pathway by activating Ras and protein phosphatase 2A (PP2A), which were both essential for collagen-mediated survival $[17,106]$. Activation of PP2A is essential in the activation of c-Raf. The process by which PP2A activates Raf- 1 seems to be exerted at the level of the Ser 259 inhibitory site $[107,108]$. Dephosphorylation of this site by PP2A contributes to the release of Raf- 1 from 143-3 inhibitory proteins and facilitates Raf-1's translocation to the membrane and interaction with active Ras, leading to Raf- 1 activation. Interestingly, fibronectin also activates Ras in malignant $\mathrm{T}$ cells, but, unlike collagen $\mathrm{I}$, it is unable to activate PP2A and c-Raf-1 [106]. Together these studies indicate that the differential ability of $\beta 1$ integrin members to protect malignant $\mathrm{T}$ cells from Fas-induced apoptosis could at least partially be due to their ability to activate the PP2A/cRaf/ERK pathway. Collagen-I-mediated activation of the MAPK/ERK pathway in Jurkat $\mathrm{T}$ cells also involves FAK [109]. A model summarizing how $\alpha 2 \beta 1$ integrin signaling inhibits Fas-induced apoptosis of the leukemic Jurkat $\mathrm{T}$ cells is depicted in Figure 3.

(2) Role of ECM/Integrin Signaling in the Chemoresistance of Malignant $T$ Cells. In addition to Fas-induced apoptosis, evidence suggests that integrin signaling can also promote chemoresistance of malignant $\mathrm{T}$ cells. It has been reported that bone marrow stromal cells enhance the survival of T-ALL cell lines and blasts partially through the LFA-1 ( $\beta 2$ integrin)/ICAM-1 adhesion signaling system [110]. In addition, adhesion of Jurkat $\mathrm{T}$ cells to bone marrow stromal cells also provides them with a survival advantage against dexamethasone-induced apoptosis [111]. Given the functional role of $\alpha 2 \beta 1$ on death receptor-mediated apoptosis, we have studied if $\alpha 2 \beta 1$ integrin signaling modulates druginduced apoptosis in malignant $\mathrm{T}$ cells. We showed that ligation of $\alpha 2 \beta 1$ integrin with collagen I significantly reduced doxorubicin-induced apoptosis of T-ALL cell lines Jurkat, HSB-2, and CEM [112]. We demonstrated that collagen I inhibited doxorubicin-induced apoptosis by inhibiting the expression of the receptor-activator of $\mathrm{NF} \kappa \mathrm{B}$-ligand (RANKL) [112]. RANKL is a cytokine of the TNF family, which binds to its receptor RANK as initially documented in osteoclast precursors and dendritic cells [113]. RANKL is expressed on osteoblasts and other mesenchymal cells as well as on activated T cells. During cognate cell-cell interactions, RANKL expressed on activated T cells induces the activation and survival of dendritic cells and osteoclast precursors [113]. Although RANK does not possess death domains [114] and thus is not coupled to DISC formation and caspase- 8 activation, it has nevertheless been implicated in cell apoptosis [115]. Activation of RANK signaling in the absence of serum induces apoptosis of RAW macrophages [116]. Moreover, we and others have shown that RANKL is implicated in doxorubicin-induced apoptosis of leukemia T-cell lines $[112,117]$. RANKL/RANK pathway participates in doxorubicin-induced apoptosis by contributing to the release of cytochrome $c$ from the mitochondria [117]. Thus, by inhibiting the expression of RANKL, collagen $I / \alpha 2 \beta 1$ integrin signaling can contribute to reduced druginduced cytochrome $\mathrm{c}$ release and protect the cells from chemotherapy.

Ligation of different $\beta 1$ integrins with ECM proteins including collagen I and fibronectin was also shown to confer resistance to Ara-C- and radiation-induced apoptosis [118]. This was demonstrated upon overexpression of $\beta 1$ integrins in HL-60 and Jurkat leukemia cell lines. The mechanism accounting for fibronectin/ $\beta 1$ integrin-dependent survival, at least in HL-60 cells, involves activation of the PI 3kinase/AKT pathway, which inhibits caspase- 8 activation. In our studies, we found that collagen I did not activate AKT in Jurkat $\mathrm{T}$ cells, and it was the collagen-mediated activation of MAPK/ERK that inhibited caspase-8 activation [17]. Further observations suggested that collagen-mediated MAPK/ERK also inhibited doxorubicin-induced RANKL expression and 


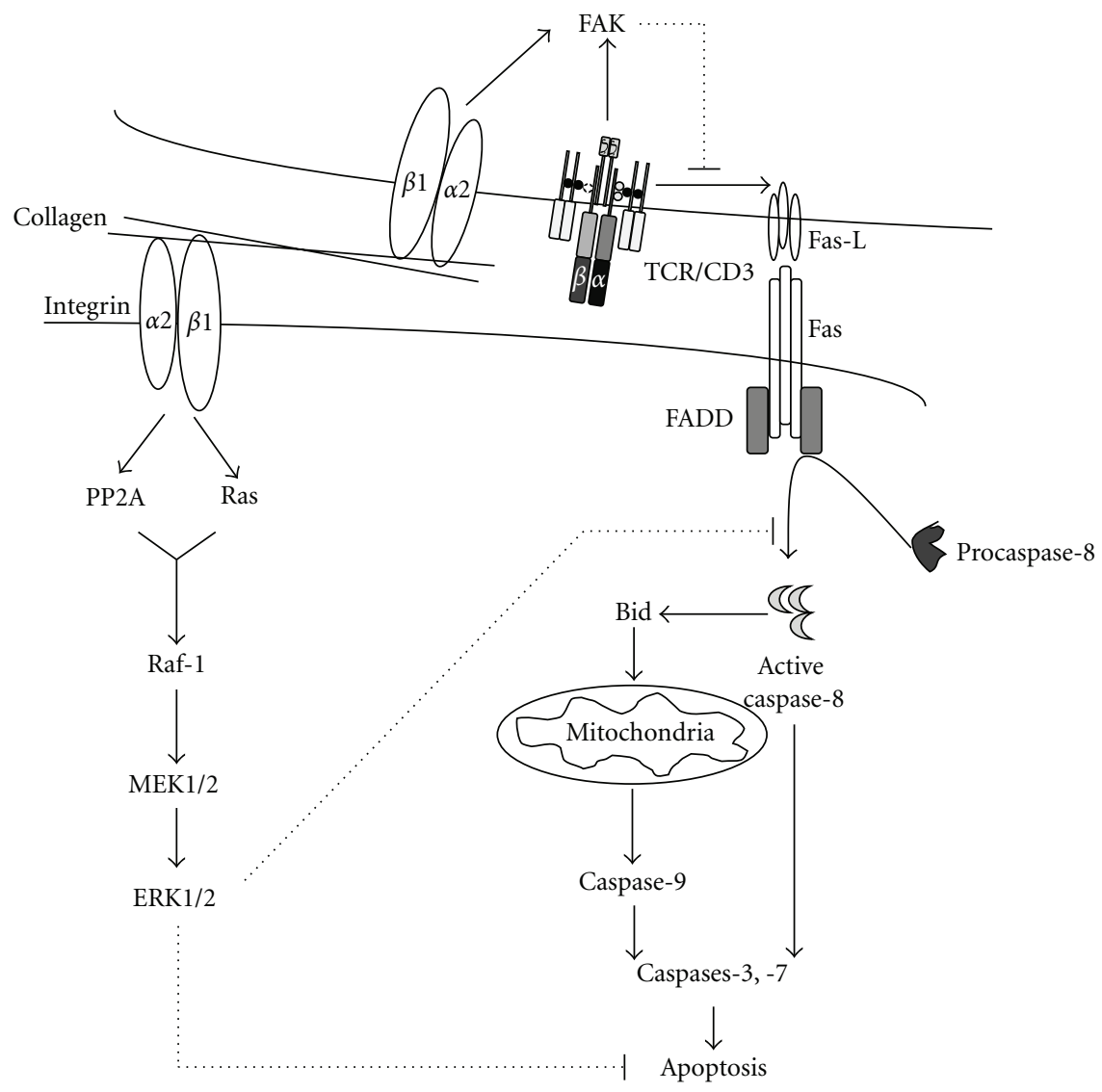

Figure 3: Model for collagen I/ $\alpha 2 \beta 1$-dependent inhibition of AICD in T cells. Ligation of the $\alpha 2 \beta 1$ integrin in the context of TCR/CD3 activation leads to the synergistic activation of FAK, which leads to the reduction of TCR-induced Fas-L expression. Ligation of $\alpha 2 \beta 1$ with collagen I also induces the activation of the MAPK/ERK through the activation of Ras, protein phosphatase 2A (PP2A), and Raf-1. Active ERK inhibits Fas-induced signaling cascade by inhibiting caspase-8 processing and activation.

fibronectin, which is a weak activator of MAPK/ERK, did not protect from doxorubicin-induced apoptosis and had no effect on RANKL expression (our unpublished data). A model by which collagen inhibits doxorubicin-induced apoptosis of T-ALL cells is depicted in Figure 4.

The studies reviewed in this section indicate that collagen-binding integrins can protect malignant $\mathrm{T}$ cells from chemotherapy. Along these lines, Cleaver et al. recently reported that $\alpha 2 \beta 1$ integrin mRNA expression levels correlated with the resistance of pediatric T-ALL to the treatment with glucocorticoids [119]. Collagen I also protected Jurkat $\mathrm{T}$ cells from serum starvation-induced apoptosis by a mechanism involving activation of FAK/MAPK/ERK pathway [109]. Thus, it appears that collagen and its receptors via the activation of the MAPK/ERK pathway constitute a major survival pathway in malignant $\mathrm{T}$ cells. These findings are in contrast to those made in other hematological malignancies in which the $\alpha 4 \beta 1$ integrin is the main molecule mediating survival and drug resistance. This suggests that, depending on the cell type, hematological tumors could respond differently to their tissue microenvironment depending on the integrin expression profile and on the signaling events that become active in the cells upon integrin-ECM interaction.

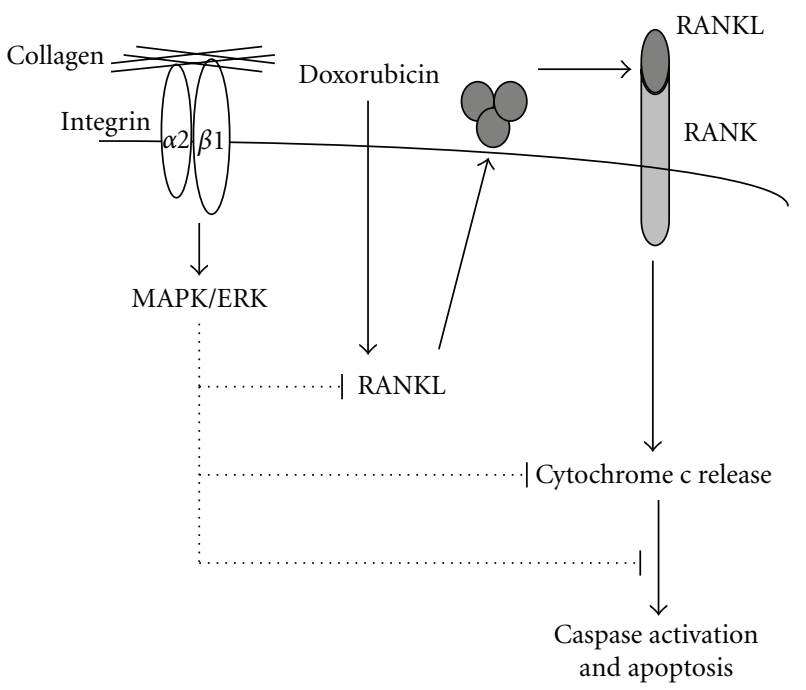

Figure 4: Model for collagen I/ $\alpha 2 \beta 1$-mediated inhibition of drug-induced apoptosis in malignant T cells. Ligation of $\alpha 2 \beta 1$ integrin activates the MAPK/ERK, which blocks doxorubicininduced RANKL expression. In turn, this leads to the reduction of cytochrome $\mathrm{c}$ release from the mitochondria and to the subsequent reduction of caspase activation and apoptosis. 


\section{Cooperation between Integrin and Growth Factor and Cytokine Receptors in Cell Survival and Chemoresistance}

In addition to ECM, tumor cells also interact with soluble factors such as growth factors and cytokines that are present in their microenvironment. Integrins signal both independently and in collaboration with growth factor receptor signaling. The crosstalk signaling between integrins and growth factor and cytokine receptors has been investigated in a number of cell types and has been outstandingly reviewed $[3,120]$. Integrins provide help to growth factor receptors by organizing signaling platforms for growth factor signaling and can directly activate growth factor receptors in a ligandindependent manner. In turn, activation of growth factor receptors can lead to increased integrin expression and avidity leading to enhanced cell adhesion and signaling. Integrins and growth factor receptors activate similar signaling pathways and likely cooperate regarding activation of the survival pathways MAPK/ERK and PI3 kinase/AKT $[1,3]$.

Growing evidence indicates that the chemokine receptor CXCR4 cooperates with $\beta 1$ integrins in mediating drug resistance of tumor cells. CXCR4 is the receptor for the stromal cell-derived factor-1 (SDF-1/CXC12), which is widely expressed in numerous tissues. It has been reported that small cell lung cancer cells express functional CXCR4 receptors and their activation with SDF-1 increases lung cancer cell adhesion to collagen I and fibronectin via $\alpha 2 \beta 1$, $\alpha 4 \beta 1$ and $\alpha 5 \beta 1$ integrins, respectively [121]. In addition, SDF-1 simulation enhances $\beta 1$ integrin-mediated resistance against etoposide-induced apoptosis [121]. Mantle cell lymphomas also express high levels of chemokine receptors CXCR4, CXCR5, and integrin $\alpha 4 \beta 1$. These receptors were shown to be critical in adhesion of lymphoma cells to bone marrow stromal cells and also in their resistance against fludarabine-induced apoptosis [122]. Thus, CXCR4 inhibitors coupled with anti- $\alpha 4 \beta 1$ integrin antibodies were shown to abrogate both adhesion and chemoresistance of mantle cell lymphoma. Recently, it has been demonstrated that bone marrow stromal cell-induced chemoresistance of acute B-cell lymphoblastic leukemia (B-ALL) is mediated via a signaling complex composed of integrin $\alpha 4 \beta 1$, the chemokine receptor CXCR4, and the human ether-à-go-gorelated gene channel (hERG1) [123]. Coculture of B-ALLs with bone marrow stromal cells induced the expression of the three receptors at the cell surface. The use of specific inhibitors indicated that all three receptors were necessary to protect B-ALLs from chemotherapy (doxorubicine, methotrexate, prednisone). This protective effect involves activation of both MAPK/ERK and PI 3-kinase/AKT survival pathways, which were shown to be activated by the assembled signaling complex. Interestingly, the use of hEGR-1 channel blockers was able to reverse drug resistance both in B-ALL blasts and in NOD/SCID mice engrafted with B-ALLs [123].

Chemokine receptor (CXCR4) and integrin $\alpha 4 \beta 1$ mediated cooperative signaling seems also to involve activation of the Spleen tyrosine kinase (SYK) in chronic lymphocytic leukemia (CLL) [124]. In these studies, activation of SYK was reported to be essential for the inhibition of fludarabine-induced apoptosis, and the protective effect of SYK was found to be mediated through the phosphorylation of AKT and increased expression of the prosurvival Bcl-2 family member Mcl-1.

Crosstalk between integrin receptors and the Wnt signaling pathway has also been shown to modulate the chemosensitivity of acute myeloid leukemia cells (AMLs) [125]. Adhesion of AMLs to fibronectin and Wnt antagonists induced independently AMLs' resistance towards daunorubicin. The protective effect of both pathways seems to require activation of the glycogen synthase kinase 3 beta (GSK3 $\beta$ ) and NF $\kappa$ B. These studies also established a link between adhesion and Wnt signaling in a coculture of the myeloid leukemic U937 cells and osteoblastic cells. Adhesion of U937 cells to osteoblastic cells was shown to induce the release of Wnt antagonist sFRP-1 from osteoblastic cells, which supported resistance to daunorubicin.

Taken together, these studies indicate that several membrane receptors are likely to regulate integrin prosurvival function. Identification of these receptors will offer new possibilities for drug targeting and inhibition of integrinmediated drug resistance.

\section{Other ECM Receptors and Mechanisms in Tumor Cell Survival and Drug Resistance}

Although not discussed above in great detail, several non$\beta 1$ integrins can also mediate drug resistance in tumor cells. For example, vitronectin through $\alpha \mathrm{v} \beta 3$ and $\alpha \mathrm{v} \beta 5$ integrins protects glioma cells from chemotherapy [9], and the angiogenic inducer CYR61, via $\alpha \mathrm{v} \beta 3$, mediates resistance of breast cancer cell lines to taxol-induced apoptosis through activation of the MAPK/ERK pathway [126].

Apart from the integrin-family of adhesion receptors, additional receptors expressed on mammalian cells also bind ECM. Herein, we will discuss the discoidin domain receptors (DDRs), which serve as receptors for several types of collagens. Originally, the DDR was described in breast cancer cells as an orphan tyrosine kinase receptor that has an extracellular discoidin-I-like domain similar to that found in the lectin of Dictyostelium discoideum [127]. DDRs are transmembrane tyrosine kinase receptors which are activated by various forms of collagens [128-130]. Two major related receptors, namely, DDR1 and DDR2, have been described, with DDR1 expressed as five isoforms (a-e) [131]. Ligation of DDRs with collagens leads to the dimerization of the receptor, which triggers the activation of the tyrosine kinase domain that leads to the autophosphorylation of tyrosine residues and to subsequent intracellular signaling [128130]. The mechanism(s) of the crosstalk signaling between DDRs and integrins are unclear, but DDRs can bind and be activated by collagens independently from $\beta 1$ integrins [132]. DDRs regulate several cellular functions including cell adhesion and migration, and proliferation.

Growing evidence indicates that DDR1 is associated with tumorigenesis. DDR1 has been shown to be expressed in various human tumors including lung [133, 134], breast $[127,135]$, ovary $[136,137]$, and brain $[138,139]$ and 
to be associated with the production of metalloproteinases and cancer cell invasion of stroma tissues during metastasis $[138,140,141]$. DDR1 is one of the several tyrosine kinase genes that carries somatic mutations in small cell lung cancer and acute myeloid leukemia [142, 143]. In addition, DDR1 has been identified as a target for the Abl kinase inhibitor imatinib [134]. DDR1 also promotes cell survival in response to genotoxic stress. Irradiation treatment of p53-positive cancer cells induces in a p53-dependent manner the expression of DDR1, which activates the MAPK/ERK pathway leading to increased expression of $\mathrm{p} 21, \mathrm{p} 19$, and $\mathrm{Bcl}-\mathrm{xL}$ and to cell survival [144]. In addition, DDR1 activation with collagen I also inhibits DNA-damage response in lung cancer cells via activation of Notch-1 signaling pathway [145]. Activation of DDR1 also protects breast cancer cells from DNA damage-induced apoptosis by inducing the expression of cyclooxygenase-2 through activation of $\mathrm{NF} \kappa \mathrm{B}$ [146]. Although DDR1 signaling and physiological functions are still not well understood, these studies underscore the notion that these collagen receptors can also be important mediators of cancer cell invasion, survival, and chemoresistance.

The use of three-dimensional (3D) cell culture models has revealed that, in addition to intracellular signaling activated by ECM receptors, resistance of tumor cells to chemotherapy can also be regulated by the physical barrier that the ECM presents to the tumor tissue, which could limit the penetration of the drugs into tumor cells. Several studies have reported that cell-adhesion-mediated drug resistance in various tumor cell spheroids models is more profound than that seen in tumor cells grown on 2D matrices [147152]. The 3D form of collagen I has been appreciated as a major barrier contributing to chemoresistance [153157]. However, care should be taken when interpreting these results, as $3 \mathrm{D}$ architecture, compared to $2 \mathrm{D}$ culture conditions, may also contribute to differences in intracellular signaling that can in turn affect tumor cell survival and drug responsiveness.

The tumor tissue in vivo is characterized by a high interstitial fluid pressure, which is due in part to tumorstromal production and organization of collagen I. This high interstitial fluid pressure is a major factor in the formation of tumor barrier to transcapillary transport [158], and has been shown to exist in several types of tumors such as breast and colorectal cancers $[159,160]$, metastatic melanoma $[161,162]$, and head and neck carcinoma [163]. It is inversely correlated with intratumoral uptake of various molecules such as antibodies [164] and chemotherapy [165]. In this regard, the intratumoral collagen I of human ovarian cancer xenografts (SKOV-3 and OVCAR-3) reduces the transport of intraperitoneally injected antibody into the tumor parenchyma, and treatment with collagenases has been shown to enhance antibody penetration in the tumors [166]. Targeting tumor-associated fibroblasts also improves cancer chemotherapy by increasing intratumoral drug uptake [167]. These studies suggest that the interstitial matrix barrier may need to be overcome before effective drug or antibody delivery can take place and that such barrier contributes to the complex role that cell adhesion and ECM play in tumor chemoresistance.

\section{Integrins in Cancer Stem Cells}

Cancer stem cells also defined as tumor-initiating cells are a minor subpopulation of tumor cells that are critical for tumor maintenance, metastasis, and therapeutic resistance. Recent studies have shown that adhesion to ECM can also regulate the tumorigenesis of these cancer subpopulations by regulating their homing to their niches, their maintenance in the niche and by regulating their proliferation and self-renewal [168]. One important molecule that has been described in this process is the CD44; the receptor for hyaluronic acid. CD44 is expressed on several types of cancer stem cells including breast, prostate, glioma as well as on leukemia initiating cells [169]. CD44 can regulate cancer stem cell tumorigenesis by promoting matrix assembly, allowing the local concentration of glycosaminoglycanassociating proteins such as FGF2 and VEGF and promoting migration and the epithelial-mesenchymal transition, which is a critical step in invasion and metastasis [169]. The $\alpha 6$ integrin also regulates self-renewal and proliferation of glioblastoma stem cells [170], and CD44 and $\alpha 2 \beta 1$ integrin regulate tumorigenesis of prostate cancer stem cells [171, 172]. Expression of integrin $\alpha \mathrm{v}$ is also required for the acquisition of a metastatic stem/progenitor cell phenotype in human prostate cancer [173], and vitronectin/ $\alpha \mathrm{v} \beta 3$ interaction also induces breast and prostate cancer stem cell differentiation and tumor formation [174].

Although the mechanisms accounting for the resistance of cancer stem cells are not yet clear, the rapid drug elimination by drug transporters could explain their resistance to chemotherapy $[175,176]$. CD44 can also contribute to this process. Indeed, CD44 has been reported to upregulate the expression of the Pg-p drug transporter by a positive feedback involving hyaluronan, PI3 Kinase, and ErbB2 [177]. CD44 can also regulate drug resistance by modulating glucose metabolism in cancer cells [178]. In addition, it has been reported that the Y-box binding protein-1 (YB1 ), an oncogenic transcription/translation factor, which is expressed in more than $40 \%$ of breast cancers, induces the expression of CD44 and of $\alpha 6$ integrin, which led to enhanced self-renewal, mammosphere growth, and resistance to paclitaxel treatment [179]. The $\beta 3$ integrin has been involved in the survival of breast tumor-initiating cells [180]. These studies suggest that adhesion of cancer stem cells to ECM is likely to contribute to their drug resistance as well. However, additional studies are required to understand the role and the underlying mechanisms of integrins in drug resistance of cancer stem cells.

\section{Concluding Remarks}

It is recognized that the tumor microenvironment plays a critical role in cancer cell survival and progression. The studies reviewed here support a general function of ECM/ integrin signaling in tumor cell survival and in the development of chemoresistance. ECM/integrin signaling pathway can, therefore, constitute a major pathway contributing to minimal residual disease and patient relapse, and its targeting 
could significantly improve anticancer therapy and patient survival.

Because of their known role in angiogenesis and migration, several integrin inhibitors are being developed as therapeutic agents for cancer [181]. A humanized anti$\alpha v \beta 3$ antibody and cyclic peptide inhibitors of integrin $\alpha \mathrm{v} \beta 3 / \alpha \mathrm{v} \beta 5$ as well as a humanized anti- $\alpha 5 \beta 1$ antibody are currently in clinical trials in several types of cancer such as glioblastoma, breast cancer, and melanoma. An additional approach to alleviate cell-adhesion-mediated drug resistance is the development of new drugs of which the cytotoxic effects are not modulated by ECM/integrin signaling. In this regard, the proteosome inhibitor bortezomib, the $\beta 1$ integrin antagonist HYD1, and statins can represent promising drugs. These three agents overcome cell-adhesion-mediated drug resistance in multiple myeloma either through the downmodulation of $\alpha 4 \beta 1$ integrin expression, or in the case of statins, via geranylgeranylation of Rho protein and activation of Rho kinase [182-184]. Future studies should also investigate if anti-integrin antagonists used in combination with current chemotherapeutic drugs can be beneficial in preventing drug resistance and patient relapse. Further understanding of tumor-stroma interactions, the contribution of integrins to cancer stem cell survival and drug resistance as well as the determination of the complete integrin "signalosome" may lead to the identification of novel therapeutic targets.

\section{References}

[1] F. G. Giancotti and E. Ruoslahti, "Integrin signaling," Science, vol. 285, no. 5430, pp. 1028-1032, 1999.

[2] J. D. Hood and D. A. Cheresh, "Role of integrins in cell invasion and migration," Nature Reviews Cancer, vol. 2, no. 2, pp. 91-100, 2002.

[3] J. W. Lee and R. Juliano, "Mitogenic signal transduction by integrin- and growth factor receptor-mediated pathways," Molecules and Cells, vol. 17, no. 2, pp. 188-202, 2004.

[4] S. M. Frisch and H. Francis, "Disruption of epithelial cell-matrix interactions induces apoptosis," Journal of Cell Biology, vol. 124, no. 4, pp. 619-626, 1994.

[5] J. E. Meredith, B. Fazeli, and M. A. Schwartz, "The extracellular matrix as a cell survival factor," Molecular Biology of the Cell, vol. 4, no. 9, pp. 953-961, 1993.

[6] S. H. Kaufmann and W. C. Earnshaw, "Induction of apoptosis by cancer chemotherapy," Experimental Cell Research, vol. 256, no. 1, pp. 42-49, 2000.

[7] T. Sethi, R. C. Rintoul, S. M. Moore et al., "Extracellular matrix proteins protect small cell lung cancer cells against apoptosis: a mechanism for small cell lung cancer growth and drug resistance in vivo," Nature Medicine, vol. 5, no. 6, pp. 662-668, 1999.

[8] J. S. Damiano, A. E. Cress, L. A. Hazlehurst, A. A. Shtil, and W. S. Dalton, "Cell adhesion mediated drug resistance (CAM-DR): role of integrins and resistance to apoptosis in human myeloma cell lines," Blood, vol. 93, no. 5, pp. 16581667, 1999.

[9] J. H. Uhm, N. P. Dooley, A. P. Kyritsis, J. S. Rao, and C. L. Gladson, "Vitronectin, a glioma-derived extracellular matrix protein, protects tumor cells from apoptotic death," Clinical Cancer Research, vol. 5, no. 6, pp. 1587-1594, 1999.
[10] N. Cordes, "Integrin-mediated cell-matrix interactions for prosurvivaland antiapoptotic signaling after genotoxic injury," Cancer Letters, vol. 242, no. 1, pp. 11-19, 2006.

[11] S. Hehlgans, M. Haase, and N. Cordes, "Signalling via integrins: implications for cell survival and anticancer strategies," Biochimica et Biophysica Acta, vol. 1775, no. 1, pp. 163-180, 2007.

[12] M. B. Meads, R. A. Gatenby, and W. S. Dalton, "Environment-mediated drug resistance: a major contributor to minimal residual disease," Nature Reviews Cancer, vol. 9, no. 9, pp. 665-674, 2009.

[13] M. B. Meads, L. A. Hazlehurst, and W. S. Dalton, "The bone marrow microenvironment as a tumor sanctuary and contributor to drug resistance," Clinical Cancer Research, vol. 14, no. 9, pp. 2519-2526, 2008.

[14] K. H. Shain and W. S. Dalton, "Environmental-mediated drug resistance: a target for multiple myeloma therapy," Expert Review of Hematology, vol. 2, no. 6, pp. 649-662, 2009.

[15] F. Aoudjit and K. Vuori, "Engagement of the alpha2beta1 integrin inhibits Fas ligand expression and activationinduced cell death in $\mathrm{T}$ cells in a focal adhesion kinasedependent manner," Blood, vol. 95, no. 6, pp. 2044-2051, 2000.

[16] M. Fornaro, J. Plescia, S. Chheang et al., "Fibronectin protects prostate cancer cells from tumor necrosis factor- $\alpha$ induced apoptosis via the AKT/survivin pathway," Journal of Biological Chemistry, vol. 278, no. 50, pp. 50402-50411, 2003.

[17] S. Gendron, J. Couture, and F. Aoudjit, "Integrin $\alpha 2 \beta 1$ inhibits Fas-mediated apoptosis in T lymphocytes by protein phosphatase 2A-dependent activation of the MAPK/ERK pathway," Journal of Biological Chemistry, vol. 278, no. 49, pp. 48633-48643, 2003.

[18] D. Lane, N. Goncharenko-Khaider, C. Rancourt, and A. Piché, "Ovarian cancer ascites protects from TRAIL-induced cell death through $\alpha \mathrm{v} \beta 5$ integrin-mediated focal adhesion kinase and Akt activation," Oncogene, vol. 29, no. 24, pp. 3519-3531, 2010.

[19] K. H. Shain, T. H. Landowski, and W. S. Dalton, "Adhesionmediated intracellular redistribution of c-Fas-associated death domain-like IL-1-converting enzyme-like inhibitory protein-long confers resistance to CD95-induced apoptosis in hematopoietic cancer cell lines," Journal of Immunology, vol. 168, no. 5, pp. 2544-2553, 2002.

[20] P. H. Krammer, R. Arnold, and I. N. Lavrik, "Life and death in peripheral T cells," Nature Reviews Immunology, vol. 7, no. 7, pp. 532-542, 2007.

[21] M. S. Ricci and W. X. Zong, "Chemotherapeutic approaches for targeting cell death pathways," Oncologist, vol. 11, no. 4, pp. 342-357, 2006.

[22] A. Strasser, H. Puthalakath, L. A. O'Reilly, and P. Bouillet, "What do we know about the mechanisms of elimination of autoreactive T and B cells and what challenges remain," Immunology and Cell Biology, vol. 86, no. 1, pp. 57-66, 2008.

[23] G. Kroemer and J. C. Reed, "Mitochondrial control of cell death," Nature Medicine, vol. 6, no. 5, pp. 513-519, 2000.

[24] J.-C. Martinou and R. Youle, "Mitochondria in apoptosis: Bcl-2 family members and mitochondrial dynamics," Developmental Cell, vol. 21, no. 1, pp. 92-101, 2011.

[25] K. C. Zimmermann, C. Bonzon, and D. R. Green, "The machinery of programmed cell death," Pharmacology and Therapeutics, vol. 92, no. 1, pp. 57-70, 2001.

[26] S. Fulda, "Tumor resistance to apoptosis," International Journal of Cancer, vol. 124, no. 3, pp. 511-515, 2009. 
[27] S. Fulda and K. M. Debatin, "Targeting apoptosis pathways in cancer therapy," Current Cancer Drug Targets, vol. 4, no. 7, pp. 569-576, 2004.

[28] R. O. Hynes, "Integrins: bidirectional, allosteric signaling machines," Cell, vol. 110, no. 6, pp. 673-687, 2002.

[29] R. C. Liddington and M. H. Ginsberg, "Integrin activation takes shape," Journal of Cell Biology, vol. 158, no. 5, pp. 833839, 2002.

[30] K. Vuori, "Integrin signaling: tyrosine phosphorylation events in focal adhesions," Journal of Membrane Biology, vol. 165, no. 3, pp. 191-199, 1998.

[31] G. E. Hannigan, P. C. McDonald, M. P. Walsh, and S. Dedhar, "Integrin-linked kinase: not so pseudo after all," Oncogene, vol. 30, no. 43, pp. 4375-4385, 2011.

[32] S. K. Mitra and D. D. Schlaepfer, "Integrin-regulated FAK-Src signaling in normal and cancer cells," Current Opinion in Cell Biology, vol. 18, no. 5, pp. 516-523, 2006.

[33] C. Horbinski, C. Mojesky, and N. Kyprianou, "Live free or die: tales of homeless (cells) in cancer," American Journal of Pathology, vol. 177, no. 3, pp. 1044-1052, 2010.

[34] D. G. Stupack and D. A. Cheresh, "Get a ligand, get a life: integrins, signaling and cell survival," Journal of Cell Science, vol. 115, no. 19, pp. 3729-3738, 2002.

[35] W. Guo and F. G. Giancotti, "Integrin signalling during tumour progression," Nature Reviews Molecular Cell Biology, vol. 5, no. 10, pp. 816-826, 2004.

[36] J. C. Loftus, J. W. Smith, and M. H. Ginsberg, "Integrinmediated cell adhesion: the extracellular face," Journal of Biological Chemistry, vol. 269, no. 41, pp. 25235-25238, 1994.

[37] F. Aoudjit and K. Vuori, "Integrin signaling inhibits paclitaxel-induced apoptosis in breast cancer cells," Oncogene, vol. 20, no. 36, pp. 4995-5004, 2001.

[38] J. M. Rae, C. J. Creighton, J. M. Meck, B. R. Haddad, and M. D. Johnson, "MDA-MB-435 cells are derived from M14 Melanoma cells - a loss for breast cancer, but a boon for melanoma research," Breast Cancer Research and Treatment, vol. 104, no. 1, pp. 13-19, 2007.

[39] N. Cordes, M. A. Blaese, L. Plasswilm, H. P. Rodemann, and D. Van Beuningen, "Fibronectin and laminin increase resistance to ionizing radiation and the cytotoxic drug Ukrain $\AA$ in human tumour and normal cells in vitro," International Journal of Radiation Biology, vol. 79, no. 9, pp. 709-720, 2003.

[40] X. H. Yang, L. M. Flores, Q. Li et al., "Disruption of lamininintegrin-CD151-focal adhesion kinase axis sensitizes breast cancer cells to ErbB2 antagonists," Cancer Research, vol. 70, no. 6, pp. 2256-2263, 2010.

[41] C. Gutierrez and R. Schiff, "HER2: biology, detection, and clinical implications," Archives of Pathology and Laboratory Medicine, vol. 135, no. 1, pp. 55-62, 2011.

[42] D. Lesniak, Y. Xu, J. Deschenes et al., " $\beta 1$-integrin circumvents the antiproliferative effects of trastuzumab in human epidermal growth factor receptor-2-positive breast cancer," Cancer Research, vol. 69, no. 22, pp. 8620-8628, 2009.

[43] C. Spangenberg, E. U. Lausch, T. M. Trost et al., "ERBB2mediated transcriptional up-regulation of the $\alpha 5 \beta 1$ integrin fibronectin receptor promotes tumor cell survival under adverse conditions," Cancer Research, vol. 66, no. 7, pp. 37153725, 2006.

[44] V. Folgiero, P. Avetrani, G. Bon et al., "Induction of ErbB3 expression by $\alpha 6 \beta 4$ integrin contributes to tamoxifen resistance in ER $\beta$-1-negative breast carcinomas," PLoS One, vol. 3, no. 2, article e1592, 2008.
[45] A. Lundström, J. Holmbom, C. Lindqvist, and T. Nordström, "The role of $\alpha 2 \beta 1$ and $\alpha 3 \beta 1$ integrin receptors in the initial anchoring of MDA-MB-231 human breast cancer cells to cortical bone matrix," Biochemical and Biophysical Research Communications, vol. 250, no. 3, pp. 735-740, 1998.

[46] G. van der Pluijm, H. Vloedgraven, S. Papapoulos et al., "Attachment characteristics and involvement of integrins in adhesion of breast cancer cell lines to extracellular bone matrix components," Laboratory Investigation, vol. 77, no. 6, pp. 665-675, 1997.

[47] N. E. Ramirez, Z. Zhang, A. Madamanchi et al., "The $\alpha 2 \beta 1$ integrin is a metastasis suppressor in mouse models and human cancer," Journal of Clinical Investigation, vol. 121, no. 1, pp. 226-237, 2011.

[48] Ö. D. Işeri, M. D. Kars, F. Arpaci, and U. Gündüz, "Gene expression analysis of drug-resistant MCF-7 cells: implications for relation to extracellular matrix proteins," Cancer Chemotherapy and Pharmacology, vol. 65, no. 3, pp. 447-455, 2010.

[49] E. S. Yao, H. Zhang, Y. Y. Chen et al., "Increased $\beta 1$ integrin is associated with decreased survival in invasive breast cancer," Cancer Research, vol. 67, no. 2, pp. 659-664, 2007.

[50] C. C. Park, H. J. Zhang, E. S. Yao, C. J. Park, and M. J. Bissell, " $\beta 1$ integrin inhibition dramatically enhances radiotherapy efficacy in human breast cancer xenografts," Cancer Research, vol. 68, no. 11, pp. 4398-4405, 2008.

[51] P. S. Hodkinson, T. Elliott, W. S. Wong et al., "ECM overrides DNA damage-induced cell cycle arrest and apoptosis in small-cell lung cancer cells through $\beta 1$ integrin-dependent activation of PI3-kinase," Cell Death and Differentiation, vol. 13, no. 10, pp. 1776-1788, 2006.

[52] R. C. Buttery, R. C. Rintoul, and T. Sethi, "Small cell lung cancer: the importance of the extracellular matrix," International Journal of Biochemistry and Cell Biology, vol. 36, no. 7, pp. 1154-1160, 2004.

[53] R. C. Rintoul and T. Sethi, "Extracellular matrix regulation of drug resistance in small-cell lung cancer," Clinical Science, vol. 102, no. 4, pp. 417-424, 2002.

[54] F. Oshita, Y. Kameda, M. Ikehara et al., "Increased expression of integrin $\beta 1$ is a poor prognostic factor in small-cell lung cancer," Anticancer Research, vol. 22, no. 2 B, pp. 1065-1070, 2002.

[55] F. Oshita, Y. Kameda, N. Hamanaka et al., "High expression of integrin $\beta 1$ and $\mathrm{p} 53$ is a greater poor prognostic factor than clinical stage in small-cell lung cancer," American Journal of Clinical Oncology, vol. 27, no. 3, pp. 215-219, 2004.

[56] L. Ju, C. Zhou, W. Li, and L. Yan, "Integrin betal overexpression associates with resistance to tyrosine kinase inhibitor gefitinib in non-small cell lung cancer," Journal of Cellular Biochemistry, vol. 111, no. 6, pp. 1565-1574, 2010.

[57] F. Thomas, J. M. P. Holly, R. Persad, A. Bahl, and C. M. Perks, "Fibronectin confers survival against chemotherapeutic agents but not against radiotherapy in DU145 prostate cancer cells: involvement of the insulin like growth factor-1 receptor," Prostate, vol. 70, no. 8, pp. 856-865, 2010.

[58] V. Bhatia, R. V. Mula, N. L. Weigel, and M. Falzon, "Parathyroid hormone-related protein regulates cell survival pathways via integrin $\alpha 6 \beta 4$-mediated activation of phosphatidylinositol 3-kinase/Akt signaling," Molecular Cancer Research, vol. 7, no. 7, pp. 1119-1131, 2009.

[59] H. Miyamoto, T. Murakami, K. Tsuchida, H. Sugino, H. Miyake, and S. Tashiro, "Tumor-stroma interaction of human pancreatic cancer: acquired resistance to anticancer 
drugs and proliferation regulation is dependent on extracellular matrix proteins," Pancreas, vol. 28, no. 1, pp. 38-44, 2004.

[60] W. Huanwen, L. Zhiyong, S. Xiaohua, R. Xinyu, W. Kai, and L. Tonghua, "Intrinsic chemoresistance to gemcitabine is associated with constitutive and laminin-induced phosphorylation of FAK in pancreatic cancer cell lines," Molecular Cancer, vol. 8, article 125, 2009.

[61] T. S. Mantoni, S. Lunardi, O. Al-Assar, A. Masamune, and T. B. Brunner, "Pancreatic stellate cells radioprotect pancreatic cancer cells through $\beta 1$-integrin signaling," Cancer Research, vol. 71, no. 10, pp. 3453-3458, 2011.

[62] T. Armstrong, G. Packham, L. B. Murphy et al., "Type I collagen promotes the malignant phenotype of pancreatic ductal adenocarcinoma," Clinical Cancer Research, vol. 10, no. 21, pp. 7427-7437, 2004.

[63] D. Mahadevan and D. D. Von Hoff, "Tumor-stroma interactions in pancreatic ductal adenocarcinoma," Molecular Cancer Therapeutics, vol. 6, no. 4, pp. 1186-1197, 2007.

[64] S. S. Müerköster, J. Kötteritzsch, C. Geismann et al., “ $\alpha 5$ integrin is crucial for L1CAM-mediated chemoresistance in pancreatic adenocarcinoma," International Journal of Oncology, vol. 34, no. 1, pp. 243-253, 2009.

[65] H. Kiefel, M. Pfeifer, S. Bondong, J. Hazin, and P. Altevogt, "Linking L1CAM-mediated signaling to NF- $\kappa$ B activation," Trends in Molecular Medicine, vol. 17, no. 4, pp. 178-187, 2011.

[66] H. Kiefel, S. Bondong, N. Erbe-Hoffmann et al., "L1CAMintegrin interaction induces constitutive NF- $\kappa \mathrm{B}$ activation in pancreatic adenocarcinoma cells by enhancing IL- $1 \beta$ expression," Oncogene, vol. 29, no. 34, pp. 4766-4778, 2010.

[67] J. T. Pribila, A. C. Quale, K. L. Mueller, and Y. Shimizu, "Integrins and T cell-mediated immunity," Annual Review of Immunology, vol. 22, pp. 157-180, 2004.

[68] K. Kamiguchi, K. Tachibana, S. Iwata, Y. Ohashi, and C. Morimoto, "Cas- $\mathrm{L}$ is required for $\beta 1$ integrin-mediated costimulation in human T cells," Journal of Immunology, vol. 163, no. 2, pp. 563-568, 1999.

[69] J. E. Maguire, K. M. Danahey, L. C. Burkly, and G. A. Van Seventer, "T cell receptor- and $\beta 1$ integrin-mediated signals synergize to induce tyrosine phosphorylation of focal adhesion kinase (pp125(FAK)) in human T cells," Journal of Experimental Medicine, vol. 182, no. 6, pp. 2079-2090, 1995.

[70] B. Ybarrondo, A. M. O'Rourke, J. B. Mccarthy, and M. F. Mescher, "Cytotoxic T-lymphocyte interaction with fibronectin and vitronectin: activated adhesion and cosignalling," Immunology, vol. 91, no. 2, pp. 186-192, 1997.

[71] M. L. Dustin and A. R. De Fougerolles, "Reprograming T cells: the role of extracellular matrix in coordination of T cell activation and migration," Current Opinion in Immunology, vol. 13, no. 3, pp. 286-290, 2001.

[72] N. Hogg, M. Laschinger, K. Giles, and A. McDowall, "Tcell integrins: more than just sticking points," Journal of Cell Science, vol. 116, no. 23, pp. 4695-4705, 2003.

[73] W. H. Rao, J. M. Hales, and R. D. R. Camp, "Potent costimulation of effector $\mathrm{T}$ lymphocytes by human collagen type I," Journal of Immunology, vol. 165, no. 9, pp. 4935-4940, 2000.

[74] M. Boisvert, N. Chetoui, S. Gendron, and F. Aoudjit, "Alpha2beta1 integrin is the major collagen-binding integrin expressed on human Th17 cells," European Journal of Immunology, vol. 40, no. 10, pp. 2710-2719, 2010.
[75] M. Boisvert, S. Gendron, N. Chetoui, and F. Aoudjit, "Alpha2beta1 integrin signaling augments $\mathrm{T}$ cell receptordependent production of interferon-gamma in human $\mathrm{T}$ cells," Molecular Immunology, vol. 44, no. 15, pp. 3732-3740, 2007.

[76] S. Ben-Horin and I. Bank, "The role of very late antigen-1 in immune-mediated inflammation," Clinical Immunology, vol. 113, no. 2, pp. 119-129, 2004.

[77] M. E. Hemler, D. Glass, J. S. Coblyn, and J. G. Jacobson, "Very late activation antigens on rheumatoid synovial fluid T lymphocytes. Association with stages of T cell activation," Journal of Clinical Investigation, vol. 78, no. 3, pp. 696-702, 1986.

[78] I. Tsunoda, E. J. Terry, B. J. Marble, E. Lazarides, C. Woods, and R. S. Fujinami, "Modulation of experimental autoimmune encephalomyelitis by VLA-2 blockade," Brain Pathology, vol. 17, no. 1, pp. 45-55, 2007.

[79] A. R. De Fougerolles, A. G. Sprague, C. L. Nickerson-Nutter et al., "Regulation of inflammation by collagen-binding integrins $\alpha 1 \beta 1$ and $\alpha 2 \beta 1$ in models of hypersensitivity and arthritis," Journal of Clinical Investigation, vol. 105, no. 6, pp. 721-729, 2000.

[80] A. Ianaro, C. Cicala, A. Calignano et al., "Anti-very late antigen-1 monoclonal antibody modulates the development of secondary lesion and T-cell response in experimental arthritis," Laboratory Investigation, vol. 80, no. 1, pp. 73-80, 2000.

[81] B. M. C. Chan, J. G. P. Wong, A. Rao, and M. E. Hemler, "T cell receptor-dependent, antigen-specific stimulation of a murine $\mathrm{T}$ cell clone induces a transient, VLA protein-mediated binding to extracellular matrix," Journal of Immunology, vol. 147, no. 2, pp. 398-404, 1991.

[82] J. Ivanoff, T. Talme, and K. G. Sundqvist, "The role of chemokines and extracellular matrix components in the migration of $\mathrm{T}$ lymphocytes into three-dimensional substrata," Immunology, vol. 114, no. 1, pp. 53-62, 2005.

[83] J. L. Mobley, E. Ennis, and Y. Shimizu, "Differential activation-dependent regulation of integrin function in cultured human T-leukemic cell lines," Blood, vol. 83, no. 4, pp. 1039-1050, 1994.

[84] Y. Nojima, K. Tachibana, T. Sato, S. F. Schlossman, and C. Morimoto, "Focal adhesion kinase (pp125(FAK)) is tyrosine phosphorylated after engagement of $\alpha 4 \beta 1$ and $\alpha 5 \beta 1$ integrins on human T-lymphoblastic cells," Cellular Immunology, vol. 161, no. 1, pp. 8-13, 1995.

[85] I. Bank, E. Rapman, R. Shapiro et al., "The epidermotropic mycosis fungoides associated $\alpha 1 \beta 1$ integrin (VLA$1, \mathrm{CD} 49 \mathrm{a} / \mathrm{CD} 29)$ is primarily a collagen IV receptor on malignant T cells," Journal of Cutaneous Pathology, vol. 26, no. 2, pp. 65-71, 1999.

[86] W. Sterry, V. Mielke, U. Konter, I. Kellner, and W. H. Boehncke, "Role of $\beta 1$-integrins in epidermotropism of malignant T cells," American Journal of Pathology, vol. 141, no. 4, pp. 855-860, 1992.

[87] A. L. Feldman, M. Law, E. D. Remstein et al., "Recurrent translocations involving the IRF4 oncogene locus in peripheral T-cell lymphomas," Leukemia, vol. 23, no. 3, pp. 574-580, 2009.

[88] B. Stark, S. Avigad, D. Luria et al., "Bone marrow Minimal Disseminated Disease (MDD) and Minimal Residual Disease (MRD) in childhood T-cell lymphoblastic lymphoma stage III, detected by Flow Cytometry (FC) and Real-Time Quantitative Polymerase Chain Reaction (RQ-PCR)," Pediatric Blood and Cancer, vol. 52, no. 1, pp. 20-25, 2009. 
[89] M. Ninomiya, A. Abe, A. Katsumi et al., "Homing, proliferation and survival sites of human leukemia cells in vivo in immunodeficient mice," Leukemia, vol. 21, no. 1, pp. 136142, 2007.

[90] R. Hamilton and F. R. Campbell, "Immunochemical localization of extracellular materials in bone marrow of rats," Anatomical Record, vol. 231, no. 2, pp. 218-224, 1991.

[91] G. Klein, "The extracellular matrix of the hematopoietic microenvironment," Experientia, vol. 51, no. 9-10, pp. 914926, 1995.

[92] N. E. Annels, A. J. Willemze, V. H. J. Van Der Velden et al., "Possible link between unique chemokine and homing receptor expression at diagnosis and relapse location in a patient with childhood T-ALL," Blood, vol. 103, no. 7, pp. 2806-2808, 2004.

[93] F. Aoudjit, E. F. Potworowski, T. A. Springer, and Y. StPierre, "Protection from lymphoma cell metastasis in ICAM1 mutant mice: a posthoming event," Journal of Immunology, vol. 161, no. 5, pp. 2333-2338, 1998.

[94] F. Aoudjit, E. F. Potworowski, and Y. St-Pierre, "The metastatic characteristics of murine lymphoma cell lines in vivo are manifested after target organ invasion," Blood, vol. 91, no. 2, pp. 623-629, 1998.

[95] D. P. Dialynas, M. J. Lee, D. P. Gold et al., "Preconditioning with fetal cord blood facilitates engraftment of primary childhood T-cell acute lymphoblastic leukemia in immunodeficient mice," Blood, vol. 97, no. 10, pp. 3218-3225, 2001.

[96] S. M. Frisch, "Evidence for a function of death-receptorrelated, death-domain-containing proteins in anoikis," Current Biology, vol. 9, no. 18, pp. 1047-1049, 1999.

[97] M. Rytömaa, L. M. Martins, and J. Downward, "Involvement of FADD and caspase-8 signalling in detachment-induced apoptosis," Current Biology, vol. 9, no. 18, pp. 1043-1046, 1999.

[98] D. R. Green, N. Droin, and M. Pinkoski, "Activation-induced cell death in T cells," Immunological Reviews, vol. 193, pp. 70$81,2003$.

[99] M. V. Richter and D. J. Topham, "The $\alpha 1 \beta 1$ integrin and TNF receptor II protect airway CD8+ effector T cells from apoptosis during influenza infection," Journal of Immunology, vol. 179, no. 8, pp. 5054-5063, 2007.

[100] S. M. Frisch and E. Ruoslahti, "Integrins and anoikis," Current Opinion in Cell Biology, vol. 9, no. 5, pp. 701-706, 1997.

[101] F. Aoudjit and K. Vuori, "Matrix attachment regulates Fasinduced apoptosis in endothelial cells: a role for c-Flip and implications for anoikis," Journal of Cell Biology, vol. 153, no. 3, pp. 633-643, 2001.

[102] K. Rosen, W. Shi, B. Calabretta, and J. Filmus, "Cell detachment triggers p38 mitogen-activated protein kinasedependent overexpression of fas ligand: a novel mechanism of anoikis of intestinal epithelial cells," Journal of Biological Chemistry, vol. 277, no. 48, pp. 46123-46130, 2002.

[103] R. N. Samara, L. M. Laguinge, and J. M. Jessup, "Carcinoembryonic antigen inhibits anoikis in colorectal carcinoma cells by interfering with Trail-R2 (DR5) signaling," Cancer Research, vol. 67, no. 10, pp. 4774-4782, 2007.

[104] T. H. Holmström, I. Schmitz, T. S. Söderström et al., "MAPK/ERK signaling in activated $\mathrm{T}$ cells inhibits CD95/Fas-mediated apoptosis downstream of DISC assembly," EMBO Journal, vol. 19, no. 20, pp. 5418-5428, 2000.

[105] X. W. Meng, J. Chandra, D. Loegering et al., "Central role of Fas-associated death domain protein in apoptosis induction by the mitogen-activated protein kinase kinase inhibitor CI1040 (PD184352) in acute lymphocytic leukemia cells in vitro," Journal of Biological Chemistry, vol. 278, no. 47, pp. 47326-47339, 2003.

[106] N. Chetoui, S. Gendron, E. Chamoux, and F. Aoudjit, "Collagen type I-mediated activation of ERK/MAP Kinase is dependent on Ras, Raf-1 and protein phosphatase $2 \mathrm{~A}$ in Jurkat T cells," Molecular Immunology, vol. 43, no. 10, pp. 1687-1693, 2006.

[107] M. Jaumot and J. F. Hancock, "Protein phosphatases 1 and 2A promote Raf-1 activation by regulating 14-3-3 interactions," Oncogene, vol. 20, no. 30, pp. 3949-3958, 2001.

[108] M. Kubicek, M. Pacher, D. Abraham, K. Podar, M. Eulitz, and M. Baccarini, "Dephosphorylation of Ser-259 regulates Raf-1 membrane association," Journal of Biological Chemistry, vol. 277, no. 10, pp. 7913-7919, 2002.

[109] K. Bijian, L. Zhang, and S. H. Shen, "Collagen-mediated survival signaling is modulated by CD45 in Jurkat T cells," Molecular Immunology, vol. 44, no. 15, pp. 3682-3690, 2007.

[110] S. S. Winter, J. J. Sweatman, M. B. Lawrence, T. H. Rhoades, A. L. Hart, and R. S. Larson, "Enhanced T-lineage acute lymphoblastic leukaemia cell survival on bone marrow stroma requires involvement of LFA-1 and ICAM-1," British Journal of Haematology, vol. 115, no. 4, pp. 862-871, 2001.

[111] D. Guo, J. Ye, L. Li, J. Dai, D. Ma, and C. Ji, “Down-regulation of Notch-1 increases co-cultured Jurkat cell sensitivity to chemotherapy," Leukemia and Lymphoma, vol. 50, no. 2, pp. 270-278, 2009.

[112] S. Gendron, J. Couture, and F. Aoudjit, "Collagen type I signalling reduces the expression and the function of human receptor activator of nuclear factor $-\kappa \mathrm{B}$ ligand (RANKL) in T lymphocytes," European Journal of Immunology, vol. 35, no. 12, pp. 3673-3682, 2005.

[113] L. E. Theill, W. J. Boyle, and J. M. Penninger, "RANK-L and RANK: T cells, bone loss, and mammalian evolution," Annual Review of Immunology, vol. 20, pp. 795-823, 2002.

[114] L. Galibert, M. E. Tometsko, D. M. Andersen, D. Cosman, and W. C. Dougall, "The involvement of multiple tumor necrosis factor receptor (TNFR)- associated factors in the signaling mechanisms of receptor activator of NF- $\kappa \mathrm{B}$, a member of the TNFR superfamily," Journal of Biological Chemistry, vol. 273, no. 51, pp. 34120-34127, 1998.

[115] A. C. Bharti and B. B. Aggarwal, "Ranking the role of RANK ligand in apoptosis," Apoptosis, vol. 9, no. 6, pp. 677-690, 2004.

[116] A. C. Bharti, Y. Takada, S. Shishodia, and B. B. Aggarwal, "Evidence that receptor activator of nuclear factor (NF) $-\kappa B$ ligand can suppress cell proliferation and induce apoptosis through activation of a NF- $\kappa$ B-independent and TRAF6dependent mechanism," Journal of Biological Chemistry, vol. 279, no. 7, pp. 6065-6076, 2004.

[117] I. Müller, S. M. Pfister, U. Grohs et al., "Receptor activator of nuclear factor $\kappa \mathrm{B}$ ligand plays a nonredundant role in doxorubicin-induced apoptosis," Cancer Research, vol. 63, no. 8, pp. 1772-1775, 2003.

[118] D. Estrugo, A. Fischer, F. Hess, H. Scherthan, C. Belka, and N. Cordes, "Ligand bound $\beta 1$ integrins inhibit procaspase8 for mediating cell adhesion-mediated drug and radiation resistance in human leukemia cells," PLoS One, vol. 2, no. 3, article e269, 2007.

[119] A. L. Cleaver, A. H. Beesley, M. J. Firth et al., "Gene-based outcome prediction in multiple cohorts of pediatric T-cell acute lymphoblastic leukemia: a Children's oncology group study," Molecular Cancer, vol. 9, article 105, 2010. 
[120] J. Ivaska and J. Heino, "Cooperation between integrins and growth factor receptors in signaling and endocytosis," Annual Review of Cell and Developmental Biology, vol. 27, pp. 291320, 2011.

[121] T. N. Hartmann, J. A. Burger, A. Glodek, N. Fujii, and M. Burger, "CXCR4 chemokine receptor and integrin signaling co-operate in mediating adhesion and chemoresistance in small cell lung cancer (SCLC) cells," Oncogene, vol. 24, no. 27, pp. 4462-4471, 2005.

[122] A. V. Kurtova, A. T. Tamayo, R. J. Ford, and J. A. Burger, "Mantle cell lymphoma cells express high levels of CXCR4, CXCR5, and VLA-4 (CD49d): importance for interactions with the stromal microenvironment and specific targeting," Blood, vol. 113, no. 19, pp. 4604-4613, 2009.

[123] S. Pillozzi, M. Masselli, E. De Lorenzo et al., "Chemotherapy resistance in acute lymphoblastic leukemia requires hERG1 channels and is overcome by hERG1 blockers," Blood, vol. 117, no. 3, pp. 902-914, 2011.

[124] M. Buchner, C. Baer, G. Prinz et al., "Spleen tyrosine kinase inhibition prevents chemokine- and integrin-mediated stromal protective effects in chronic lymphocytic leukemia," Blood, vol. 115, no. 22, pp. 4497-4506, 2010.

[125] F. De Toni, C. Racaud-Sultan, G. Chicanne et al., "A crosstalk between the Wnt and the adhesion-dependent signaling pathways governs the chemosensitivity of acute myeloid leukemia," Oncogene, vol. 25, no. 22, pp. 3113-3122, 2006.

[126] J. A. Menendez, L. Vellon, I. Mehmi, P. K. Teng, D. W. Griggs, and R. Lupu, "A novel CYR61-triggered "CYR61$\alpha v \beta 3$ integrin loop" regulates breast cancer cell survival and chemosensitivity through activation of ERK1/ERK2 MAPK signaling pathway," Oncogene, vol. 24, no. 5, pp. 761-779, 2005.

[127] J. D. Johnson, J. C. Edman, and W. J. Rutter, "Erratum: A receptor tyrosine kinase found in breast carcinoma cells has an extracellular discoidin I-like domain," Proceedings of the National Academy of Sciences of the United States of America, vol. 90, no. 22, article 10891, 1993.

[128] J. Heino, M. Huhtala, J. Käpylä, and M. S. Johnson, "Evolution of collagen-based adhesion systems," International Journal of Biochemistry and Cell Biology, vol. 41, no. 2, pp. 341-348, 2009.

[129] W. Vogel, "Discoidin domain receptors: structural relations and functional implications," FASEB Journal, vol. 13, no. 8, supplement, pp. s77-s82, 1999.

[130] W. F. Vogel, R. Abdulhussein, and C. E. Ford, "Sensing extracellular matrix: an update on discoidin domain receptor function," Cellular Signalling, vol. 18, no. 8, pp. 1108-1116, 2006.

[131] F. Alves, S. Saupe, M. Ledwon, F. Schaub, W. Hiddemann, and W. F. Vogel, "Identification of two novel, kinasedeficient variants of discoidin domain receptor 1: differential expression in human colon cancer cell lines," The FASEB Journal, vol. 15, no. 7, pp. 1321-1323, 2001.

[132] W. Vogel, C. Brakebusch, R. Fässler, F. Alves, F. Ruggiero, and T. Pawson, "Discoidin domain receptor 1 is activated independently of $\beta 1$ integrin," Journal of Biological Chemistry, vol. 275, no. 8, pp. 5779-5784, 2000.

[133] C. E. Ford, S. K. Lau, C. Q. Zhu, T. Andersson, M. S. Tsao, and W. F. Vogel, "Expression and mutation analysis of the discoidin domain receptors 1 and 2 in non-small cell lung carcinoma," British Journal of Cancer, vol. 96, no. 5, pp. 808814, 2007.
[134] K. Rikova, A. Guo, Q. Zeng et al., "Global survey of phosphotyrosine signaling identifies oncogenic kinases in lung cancer," Cell, vol. 131, no. 6, pp. 1190-1203, 2007.

[135] J. Dejmek, K. Leandersson, J. Manjer et al., "Expression and signalling activity of Wnt-5a/discoidin domain receptor-1 and Syk plays distinct but decisive roles in breast cancer patient survival," Clinical Cancer Research, vol. 11, no. 2 I, pp. 520-528, 2005.

[136] V. A. Heinzelmann-Schwarz, M. Gardiner-Garden, S. M. Henshall et al., "Overexpression of the cell adhesion molecules DDR1, claudin 3, and Ep-CAM in metaplastic ovarian epithelium and ovarian cancer," Clinical Cancer Research, vol. 10, no. 13, pp. 4427-4436, 2004.

[137] J. Quan, T. Yahata, S. Adachi, K. Yoshihara, and K. Tanaka, "Identification of receptor tyrosine kinase, discoidin domain receptor 1 (DDR1), as a potential biomarker for serous ovarian cancer," International Journal of Molecular Sciences, vol. 12, no. 2, pp. 971-982, 2011.

[138] R. Ram, G. Lorente, K. Nikolich, R. Urfer, E. Foehr, and U. Nagavarapu, "Discoidin domain receptor-1a (DDR1a) promotes glioma cell invasion and adhesion in association with matrix metalloproteinase-2," Journal of Neuro-Oncology, vol. 76, no. 3, pp. 239-248, 2006.

[139] H. L. Weiner, H. Huang, D. Zagzag, H. Boyce, R. Lichtenbaum, and E. B. Ziff, "Consistent and selective expression of the discoidin domain receptor-1 tyrosine kinase in human brain tumors," Neurosurgery, vol. 47, no. 6, pp. 1400-1409, 2000.

[140] L. Castro-Sanchez, A. Soto-Guzman, M. Guaderrama-Diaz, P. Cortes-Reynosa, and E. P. Salazar, "Role of DDR1 in the gelatinases secretion induced by native type IV collagen in MDA-MB-231 breast cancer cells," Clinical and Experimental Metastasis, vol. 28, no. 5, pp. 463-477, 2011.

[141] H. S. Park, K. R. Kim, H. J. Lee et al., "Overexpression of discoidin domain receptor 1 increases the migration and invasion of hepatocellular carcinoma cells in association with matrix metalloproteinase," Oncology Reports, vol. 18, no. 6, pp. 1435-1441, 2007.

[142] H. Davies, C. Hunter, R. Smith et al., "Somatic mutations of the protein kinase gene family in human lung cancer," Cancer Research, vol. 65, no. 17, pp. 7591-7595, 2005.

[143] M. H. Tomasson, Z. Xiang, R. Walgren et al., "Somatic mutations and germline sequence variants in the expressed tyrosine kinase genes of patients with de novo acute myeloid leukemia," Blood, vol. 111, no. 9, pp. 4797-4808, 2008.

[144] P. P. Ongusaha, J. I. Kim, L. Fang et al., "p53 induction and activation of DDR1 kinase counteract p53-mediated apoptosis and influence p53 regulation through a positive feedback loop," EMBO Journal, vol. 22, no. 6, pp. 1289-1301, 2003.

[145] H.-G. Kim, S.-Y. Hwang, S. A. Aaronson, A. Mandinova, and S. W. Lee, "DDR1 receptor tyrosine kinase promotes prosurvival pathway through Notch1 activation," Journal of Biological Chemistry, vol. 286, no. 20, pp. 17672-17681, 2011.

[146] S. Das, P. P. Ongusaha, Y. S. Yang, J. M. Park, S. A. Aaronson, and S. W. Lee, "Discoidin domain receptor 1 receptor tyrosine kinase induces cyclooxygenase- 2 and promotes chemoresistance through nuclear factor- $\kappa \mathrm{B}$ pathway activation," Cancer Research, vol. 66, no. 16, pp. 8123-8130, 2006.

[147] D. Barbone, T. M. Yang, J. R. Morgan, G. Gaudino, and V. C. Broaddus, "Mammalian target of rapamycin contributes 
to the acquired apoptotic resistance of human mesothelioma multicellular spheroids," Journal of Biological Chemistry, vol. 283, no. 19, pp. 13021-13030, 2008.

[148] A. Frankel, R. Buckman, and R. S. Kerbel, "Abrogation of Taxol-induced G2-M arrest and apoptosis in human ovarian cancer cells grown as multicellular tumor spheroids," Cancer Research, vol. 57, no. 12, pp. 2388-2393, 1997.

[149] S. K. Green, A. Frankel, and R. S. Kerbel, "Adhesiondependent multicellular drug resistance," Anti-Cancer Drug Design, vol. 14, no. 2, pp. 153-168, 1999.

[150] A. Ivascu and M. Kubbies, "Diversity of cell-mediated adhesions in breast cancer spheroids," International Journal of Oncology, vol. 31, no. 6, pp. 1403-1413, 2007.

[151] C. L. Li, T. Tian, K. J. Nan et al., "Survival advantages of multicellular spheroids vs. monolayers of HepG2 cells in vitro," Oncology Reports, vol. 20, no. 6, pp. 1465-1471, 2008.

[152] V. M. Weaver, S. Lelièvre, J. N. Lakins et al., " $\beta 4$ integrindependent formation of polarized three-dimensional architecture confers resistance to apoptosis in normal and malignant mammary epithelium," Cancer Cell, vol. 2, no. 3, pp. 205-216, 2002.

[153] S. Dangi-Garimella, S. B. Krantz, M. R. Barron et al., "Threedimensional collagen I promotes gemcitabine resistance in pancreatic cancer through MT1-MMP-mediated expression of HMGA2," Cancer Research, vol. 71, no. 3, pp. 1019-1028, 2011.

[154] T. Furukawa, T. Kubota, M. Watanabe et al., "Increased drug resistance of cultured human cancer cell lines in threedimensional cellular growth assay using collagen gel matrix," Journal of Surgical Oncology, vol. 49, no. 2, pp. 86-92, 1992.

[155] M. Kawamura, M. Gika, T. Abiko et al., "Clinical evaluation of chemosensitivity testing for patients with unresectable non-small cell lung cancer (NSCLC) using collagen gel droplet embedded culture drug sensitivity test (CD-DST)," Cancer Chemotherapy and Pharmacology, vol. 59, no. 4, pp. 507-513, 2007.

[156] E. Millerot-Serrurot, M. Guilbert, N. Fourré et al., “3D collagen type I matrix inhibits the antimigratory effect of doxorubicin," Cancer Cell International, vol. 10, article 26, 2010.

[157] I. F. Tannock, C. M. Lee, J. K. Tunggal, D. S. M. Cowan, and M. J. Egorin, "Limited penetration of anticancer drugs through tumor tissue: a potential cause of resistance of solid tumors to chemotherapy," Clinical Cancer Research, vol. 8, no. 3, pp. 878-884, 2002.

[158] C. H. Heldin, K. Rubin, K. Pietras, and A. Östman, "High interstitial fluid pressure - an obstacle in cancer therapy," Nature Reviews Cancer, vol. 4, no. 10, pp. 806-813, 2004.

[159] J. R. Less, M. C. Posner, Y. Boucher, D. Borochovitz, N. Wolmark, and R. K. Jain, "Interstitial hypertension in human breast and colorectal tumors," Cancer Research, vol. 52, no. 22, pp. 6371-6374, 1992.

[160] S. D. Nathanson and L. Nelson, "Interstitial fluid pressure in breast cancer, benign breast conditions, and breast parenchyma," Annals of Surgical Oncology, vol. 1, no. 4, pp. 333-338, 1994.

[161] Y. Boucher, J. M. Kirkwood, D. Opacic, M. Desantis, and R. K. Jain, "Interstitial hypertension in superficial metastatic melanomas in humans," Cancer Research, vol. 51, no. 24, pp. 6691-6694, 1991.

[162] B. D. Curti, W. J. Urba, W. G. Alvord et al., "Interstitial pressure of subcutaneous nodules in melanoma and lymphoma patients: changes during treatment," Cancer Research, vol. 53, no. 10 , pp. 2204-2207, 1993.
[163] R. Gutmann, M. Leunig, J. Feyh et al., "Interstitial hypertension in head and neck tumors in patients: correlation with tumor size," Cancer Research, vol. 52, no. 7, pp. 1993-1995, 1992.

[164] P. A. Netti, D. A. Berk, M. A. Swartz, A. J. Grodzinsky, and R. K. Jain, "Role of extracellular matrix assembly in interstitial transport in solid tumors," Cancer Research, vol. 60, no. 9, pp. 2497-2503, 2000.

[165] Y. Boucher, C. Brekken, P. A. Netti, L. T. Baxter, and R. K. Jain, "Intratumoral infusion of fluid: estimation of hydraulic conductivity and implications for the delivery of therapeutic agents," British Journal of Cancer, vol. 78, no. 11, pp. 14421448, 1998.

[166] J. Choi, K. Credit, K. Henderson et al., "Intraperitoneal immunotherapy for metastatic ovarian carcinoma: resistance of intratumoral collagen to antibody penetration," Clinical Cancer Research, vol. 12, no. 6, pp. 1906-1912, 2006.

[167] M. Loeffler, J. A. Krüger, A. G. Niethammer, and R. A. Reisfeld, "Targeting tumor-associated fibroblasts improves cancer chemotherapy by increasing intratumoral drug uptake," Journal of Clinical Investigation, vol. 116, no. 7, pp. 19551962, 2006.

[168] S. J. Ellis and G. Tanentzapf, "Integrin-mediated adhesion and stem-cell-niche interactions," Cell and Tissue Research, vol. 339, no. 1, pp. 121-130, 2010.

[169] M. Zöller, "CD44: can a cancer-initiating cell profit from an abundantly expressed molecule?" Nature Reviews Cancer, vol. 11, no. 4, pp. 254-267, 2011.

[170] J. D. Lathia, J. Gallagher, J. M. Heddleston et al., "Integrin Alpha 6 regulates glioblastoma stem cells," Cell Stem Cell, vol. 6, no. 5, pp. 421-432, 2010.

[171] N. J. Maitland and A. T. Collins, "Prostate cancer stem cells: a new target for therapy," Journal of Clinical Oncology, vol. 26, no. 17, pp. 2862-2870, 2008.

[172] L. Patrawala, T. Calhoun-Davis, R. Schneider-Broussard, and D. G. Tang, "Hierarchical organization of prostate cancer cells in xenograft tumors: the CD $44+\alpha 2 \beta 1+$ cell population is enriched in tumor-initiating cells," Cancer Research, vol. 67, no. 14, pp. 6796-6805, 2007.

[173] C. van den Hoogen, G. van der Horst, H. Cheung, J. T. Buijs, R. C.M. Pelger, and G. van der Pluijm, "Integrin $\alpha \mathrm{v}$ expression is required for the acquisition of a metastatic stem/progenitor cell phenotype in human prostate cancer," American Journal of Pathology, vol. 179, no. 5, pp. 2559-2568, 2011.

[174] E. M. Hurt, K. Chan, M. A. D. Serrat, S. B. Thomas, T. D. Veenstra, and W. L. Farrar, "Identification of vitronectin as an extrinsic inducer of cancer stem cell differentiation and tumor formation," Stem Cells, vol. 28, no. 3, pp. 390-398, 2010.

[175] M. Dean, T. Fojo, and S. Bates, "Tumour stem cells and drug resistance," Nature Reviews Cancer, vol. 5, no. 4, pp. 275-284, 2005.

[176] M. Maugeri-Saccà, P. Vigneri, and R. De Maria, "Cancer stem cells and chemosensitivity," Clinical Cancer Research, vol. 17, no. 15, pp. 4942-4947, 2011.

[177] S. Misra, S. Ghatak, and B. P. Toole, "Regulation of MDR1 expression and drug resistance by a positive feedback loop involving hyaluronan, phosphoinositide 3-kinase, and ErbB2," Journal of Biological Chemistry, vol. 280, no. 21, pp. 20310-20315, 2005.

[178] M. Tamada, O. Nagano, S. Tateyama et al., "Modulation of glucose metabolism by CD44 contributes to antioxidant 
status and drug resistance in cancer cells," Cancer Research, vol. 72, no. 6, pp. 1438-1448, 2012.

[179] K. To, A. Fotovati, K. M. Reipas et al., "Y-box binding protein-1 induces the expression of CD44 and CD49f leading to enhanced self-Renewal, mammosphere growth, and drug resistance," Cancer Research, vol. 70, no. 7, pp. 2840-2851, 2010.

[180] F. Yu, H. Deng, H. Yao, Q. Liu, F. Su, and E. Song, "Mir-30 reduction maintains self-renewal and inhibits apoptosis in breast tumor-initiating cells," Oncogene, vol. 29, no. 29, pp. 4194-4204, 2010.

[181] J. S. Desgrosellier and D. A. Cheresh, "Integrins in cancer: biological implications and therapeutic opportunities," Nature Reviews Cancer, vol. 10, no. 1, pp. 9-22, 2010.

[182] M. F. Emmons, A. W. Gebhard, R. R. Nair et al., "Acquisition of resistance towards HYD1 correlates with a reduction in cleaved alpha 4 integrin expression and a compromised CAM-DR phenotype," Molecular Cancer Therapeutics, vol. 10, no. 12, pp. 2257-2266, 2011.

[183] K. Noborio-Hatano, J. Kikuchi, M. Takatoku et al., "Bortezomib overcomes cell adhesion-mediated drug resistance through downregulation of VLA-4 expression in multiple myeloma," Oncogene, vol. 28, no. 2, pp. 231-242, 2009.

[184] R. Schmidmaier, P. Baumann, M. Simsek, F. Dayyani, B. Emmerich, and G. Meinhardt, "The HMG-CoA reductase inhibitor simvastatin overcomes cell adhesion-mediated drug resistance in multiple myeloma by geranylgeranylation of Rho protein and activation of Rho kinase," Blood, vol. 104, no. 6, pp. 1825-1832, 2004. 


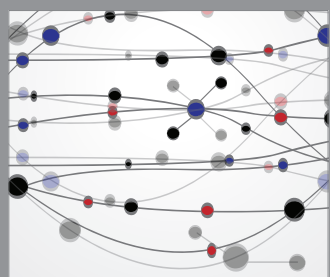

The Scientific World Journal
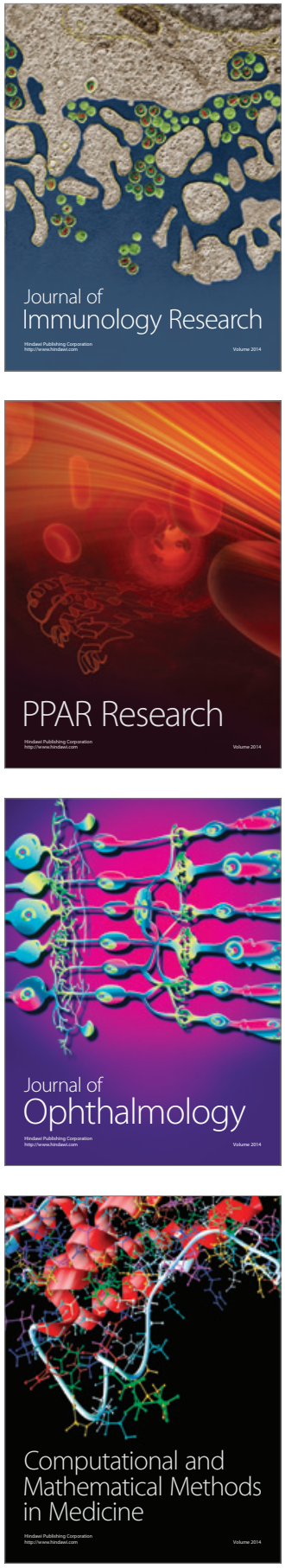

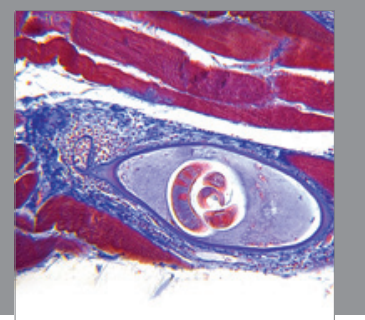

Gastroenterology

Research and Practice
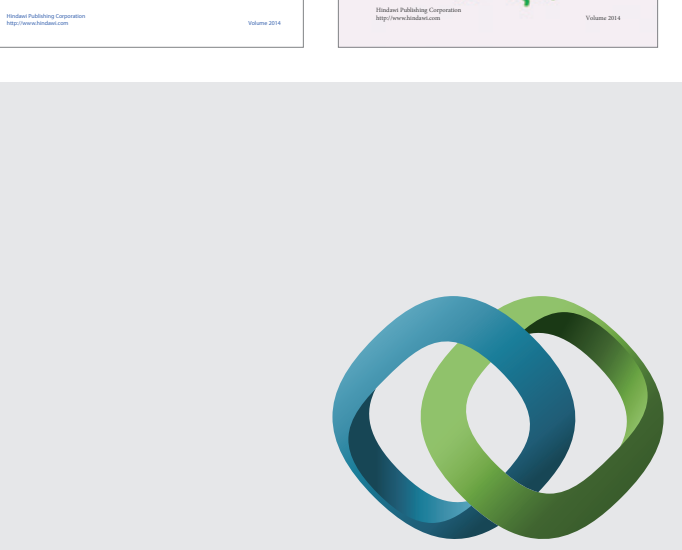

\section{Hindawi}

Submit your manuscripts at

http://www.hindawi.com
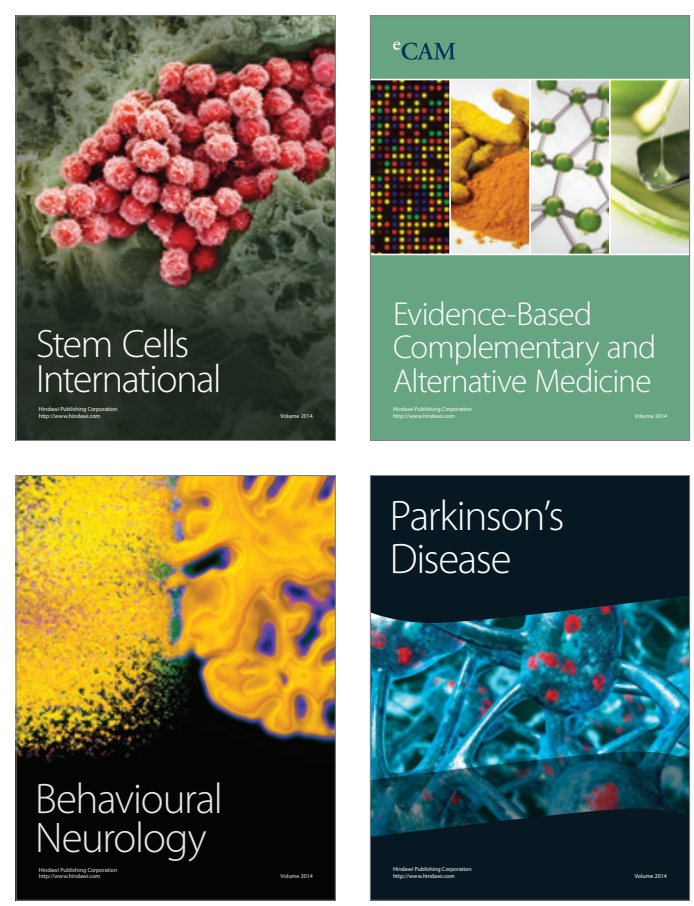

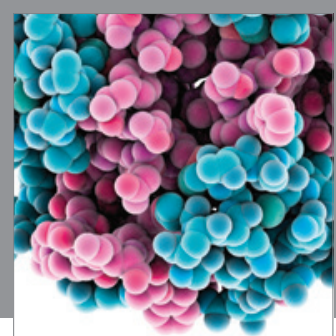

Journal of
Diabetes Research

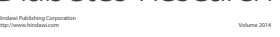

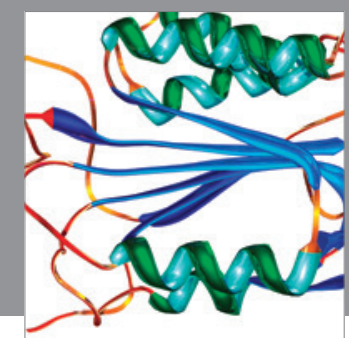

Disease Markers
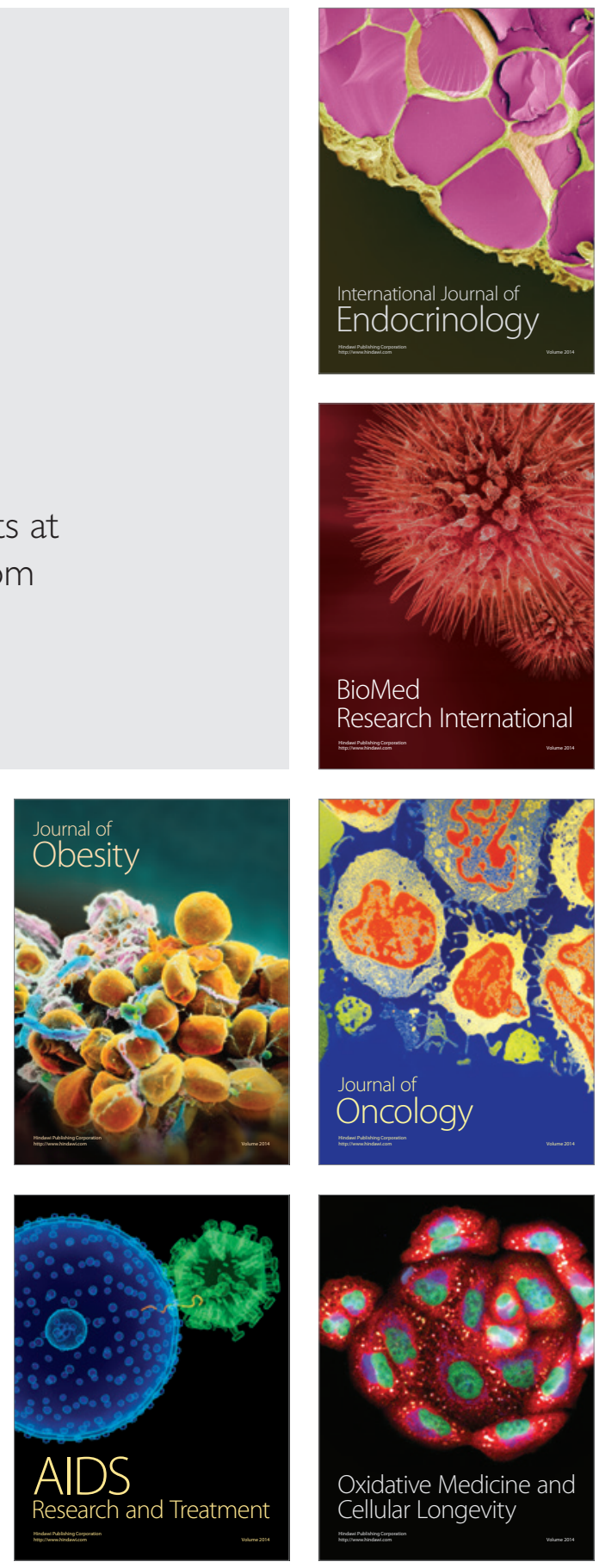